\title{
Cenozoic aridization in Central Eurasia shaped diversification of toad-headed agamas (Phrynocephalus; Agamidae, Reptilia)
}

\author{
Evgeniya N Solovyeva ${ }^{\text {Corresp., }}{ }^{1}$, Vladimir S Lebedev ${ }^{1}$, Evgeniy A Dunayev ${ }^{1}$, Roman A Nazarov $^{1}$, Anna A \\ Bannikova $^{2}$, Jing Che ${ }^{3,4}$, Robert W Murphy ${ }^{3,5}$, Nikolay A Poyarkov ${ }^{\text {Corresp. } 2}$ \\ 1 Zoological Museum, Lomonosov Moscow State University, Moscow, Russia \\ 2 Biological Faculty, Department of Vertebrate Zoology, Lomonosov Moscow State University, Moscow, Russia \\ 3 State Key Laboratory of Genetic Resources and Evolution, and Center for excellence in Animal Evolution and Genetics, Kunming Institute of Zoology, \\ Chinese Academy of Sciences, Kunming, Yunnan, China \\ 4 Southeast Asia Biodiversity Research Institute, Chinese Academy of Sciences, Yezin, Nay Pyi Taw, Myanmar \\ 5 Faculty of Arts and Science, Department of Ecology \& Evolutionary Biology, University of Toronto, Toronto, Canada \\ Corresponding Authors: Evgeniya N Solovyeva, Nikolay A Poyarkov \\ Email address: anolis@yandex.ru, n.poyarkov@gmail.com
}

We hypothesize the phylogenetic relationships of the agamid genus Phrynocephalus to assess how past environmental changes shaped the evolutionary and biogeographic history of these lizards and especially the impact of paleogeography and climatic factors. Phrynocephalus is one of the most diverse and taxonomically confusing lizard genera. As a key element of Palearctic deserts, it serves as a promising model for studies of historical biogeography and formation of arid habitats in Eurasia.

We used 51 samples representing 33 of 40 recognized species of Phrynocephalus covering all major areas of the genus. Molecular data included four mtDNA (COI, ND2, ND4, Cytb; $2703 \mathrm{bp}$ ) and four nuDNA protein-coding genes (RAG1, BDNF, AKAP9, NKTR; $4188 \mathrm{bp}$ ). AU-tests were implemented to test for significant differences between mtDNA- and nuDNA-based topologies. A time-calibrated phylogeny was estimated using a Bayesian relaxed molecular clock with 9 fossil calibrations. We reconstructed the ancestral area of origin, biogeographic scenarios, body-size and the evolution of habitat preference.

Phylogenetic analyses of nuDNA genes recovered a well-resolved and supported topology. Analyses detected significant discordance with the less-supported mtDNA genealogy. The position of $P$. mystaceus conflicted greatly between the two datasets. MtDNA introgression due to ancient hybridization best explained this result. Monophyletic Phrynocephalus contained three main clades: (I) oviparous species from south-western and Middle Asia; (II) viviparous species of Qinghai-Tibetan Plateau (QTP); and (III) oviparous species of the Caspian Basin, Middle and Central Asia. Phrynocephalus originated in late Oligocene (26.9 Ma) and modern species diversified during the middle Miocene (14.8-13.5 Ma). The reconstruction of ancestral areas indicated that Phrynocephalus originated in Middle East-southern Middle Asia. Body size miniaturization likely occurred early in the history of Phrynocephalus. The common ancestor of Phrynocephalus probably preferred sandy substrates with the inclusion of clay or gravel.

The time of Agaminae radiation and origin of Phrynocephalus in the late Oligocene significantly precedes the landbridge between Afro-Arabia and Eurasia in the Early Miocene. Diversification of Phrynocephalus coincides well with the Mid-Miocene Climatic Transition when a rapid cooling of climate drove progressing aridification and the Paratethys Salinity Crisis. These factors likely triggered the spreading of desert habitats in Central Eurasia, which Phrynocephalus occupied. The origin of the viviparous Tibetan clade has been associated traditionally with uplifting of the QTP; however, further studies are needed to confirm this. Progressing Late Miocene aridification, the decrease of the Paratethys Basin, orogenesis and 
Plio-Pleistocene climate oscillations likely promoted further diversification within Phrynocephalus. We discuss Phrynocephalus taxonomy in scope of the new analyses. 


\section{Cenozoic aridization in Central Eurasia shaped diversification of \\ 2 toad-headed agamas (Phrynocephalus; Agamidae, Reptilia)}

\section{Evgeniya N. Solovyeva ${ }^{1 *}$, Vladimir S. Lebedev ${ }^{1}$, Evgeniy A. Dunayev ${ }^{1}$, Roman}

4 A. Nazarov ${ }^{1}$, Anna A. Bannikova ${ }^{2}$, Jing Che ${ }^{3,4}$, Robert W. Murphy ${ }^{3,5}$, Nikolay

5 A. Poyarkov, Jr. ${ }^{2, *}$

6

71 Zoological Museum, Lomonosov Moscow State University, Moscow, Russia

82 Biological Faculty, Department of Vertebrate Zoology, Lomonosov Moscow State University, 9 Moscow, Russia

3 State Key Laboratory of Genetic Resources and Evolution, and Center for excellence in Animal Evolution and Genetics, Kunming Institute of Zoology, Chinese Academy of Sciences, Kunming, Yunnan, China

4 Southeast Asia Biodiversity Research Institute, Chinese Academy of Sciences, Yezin, Nay Pyi Taw, Myanmar 5 Centre for Biodiversity and Conservation Biology, Royal Ontario Museum, Toronto, Canada

\section{Abstract}

We hypothesize the phylogenetic relationships of the agamid genus Phrynocephalus to assess how past environmental changes shaped the evolutionary and biogeographic history of these lizards and especially the impact of paleogeography and climatic factors. Phrynocephalus is one of the most diverse and taxonomically confusing lizard genera. As a key element of Palearctic deserts, it serves as a promising model for studies of historical biogeography and formation of arid habitats in Eurasia.

We used 51 samples representing 33 of 40 recognized species of Phrynocephalus covering all major areas of the genus. Molecular data included four mtDNA (COI, ND2, ND4, Cytb; 2703 bp) and four nuDNA protein-coding genes (RAG1, BDNF, AKAP9, NKTR; $4188 \mathrm{bp})$. AU-tests were implemented to test for significant differences between mtDNA- and nuDNA-based topologies. 
A time-calibrated phylogeny was estimated using a Bayesian relaxed molecular clock with 9 fossil calibrations. We reconstructed the ancestral area of origin, biogeographic scenarios, bodysize and the evolution of habitat preference.

Phylogenetic analyses of nuDNA genes recovered a well-resolved and supported topology. Analyses detected significant discordance with the less-supported mtDNA genealogy. The position of $P$. mystaceus conflicted greatly between the two datasets. MtDNA introgression due to ancient hybridization best explained this result. Monophyletic Phrynocephalus contained three main clades: (I) oviparous species from south-western and Middle Asia; (II) viviparous species of Qinghai-Tibetan Plateau (QTP); and (III) oviparous species of the Caspian Basin, Middle and Central Asia. Phrynocephalus originated in late Oligocene (26.9 Ma) and modern species diversified during the middle Miocene (14.8-13.5 Ma). The reconstruction of ancestral areas indicated that Phrynocephalus originated in Middle East-southern Middle Asia. Body size miniaturization likely occurred early in the history of Phrynocephalus. The common ancestor of Phrynocephalus probably preferred sandy substrates with the inclusion of clay or gravel.

The time of Agaminae radiation and origin of Phrynocephalus in the late Oligocene significantly precedes the landbridge between Afro-Arabia and Eurasia in the Early Miocene. Diversification of Phrynocephalus coincides well with the Mid-Miocene Climatic Transition when a rapid cooling of climate drove progressing aridification and the Paratethys Salinity Crisis. These factors likely triggered the spreading of desert habitats in Central Eurasia, which Phrynocephalus occupied. The origin of the viviparous Tibetan clade has been associated traditionally with uplifting of the QTP; however, further studies are needed to confirm this. Progressing Late Miocene aridification, the decrease of the Paratethys Basin, orogenesis and Plio-Pleistocene climate oscillations likely promoted further diversification within Phrynocephalus. We discuss Phrynocephalus taxonomy in scope of the new analyses.

\section{Introduction}

Historical biogeography aims to understand the drivers of speciation including the roles played by plate tectonics and climatic change (Lomolino et al. 2006). The eastern part of the Great Palearctic Desert Belt spans from Eastern Europe to eastern China, including Middle Asia 
58

59

60

61

62

(Kazakhstan, Kyrgyzstan, Uzbekistan, Tajikistan and Turkmenistan) and Central Asia. Middle and Central Asia have one of the oldest desert areas. Desertification started at least 23.8-22.0 million years ago (Ma) (Xia \& Hu 1993; Guo et al. 2002). Various paleogeographic factors played major roles in the shifting of Central Eurasian climate (Ramstein et al. 1997). These include the Miocene retreat of the Paratethys Sea, which stretched over Eurasia $30 \mathrm{Ma}$ (Popov et al. 2004, 2009), tectonic activity in Southwest Asia (Whiteman 1978; Weise 1974; Macey et al. 1993; Golonka 2004) and the uplifting of the Qinghai-Tibetan Plateau (QTP; Harrison et al. 1992, 1995; Ramstein et al. 1997; An et al. 2001; Molnar 2005). Aridization led to the disappearance of forests and formation of desert ecosystems (Cerling et al. 1997; Ma et al. 1998) and it intensified in the late Cenozoic following the formation of Asian monsoon climate (Guo et al. 2002).

Central Eurasian deserts cradle a rich herpetofauna (Chernov 1948; Chernov 1959; Likhnova 1992; Ananjeva \& Tuniyev 1992; Szczerbak 2003). In the late Cenozoic, dramatic climatic changes influenced the origins, diversification and distribution of Central Eurasian reptiles (Macey et al. 2000; Melville et al. 2009). However, the dearth of phylogenetic and historical biogeographic studies for Central Eurasia does not allow the testing of hypotheses on the biological consequences of Cenozoic climatic events. The reptile fauna of the Central Asian deserts is particularly diverse, yet we still have limited understanding of the drivers of evolution of the constituent species (Melville et al. 2009).

The agamid genus Phrynocephalus Kaup, 1825, or toad-headed lizards, is one of the most speciose genera in its family. It contains from 28 to over 42 species and spans arid regions from northwestern China to the western side of the Caspian Sea, across the QTP, and Southwest Asia to the Arabian Peninsula (Wermuth 1965; Moody 1980; Barabanov \& Ananjeva 2007; Guo \& Wang 2007; Uetz \& Hosek 2016; Kamali \& Anderson 2015) (Fig. 1). The species are ecologically important components of the central Eurasian desert fauna and are highly adapted to sand dunes and stony montane deserts from sea level up to $6400 \mathrm{~m}$ a.s.1. (Zhao 1999). They exhibit high levels of variation in ecological and morphological diversity, and the species range from being habitat generalists to specialists (Clemann et al. 2008; Dunayev 2009). Oviparous reproduction occurs in lower elevations and yet viviparous species occur on the QTP (Zhao \& Adler 1993; Pang et al. 2003; Guo \& Wang 2007). The involvement of Phrynocephalus in socalled "substrate races" leads to much taxonomic confusion (Dunayev 2009), especially because 
89 their phylogenetic relationships and historical biogeography remain uncertain. Considerable

90

91 taxonomic, morphological, allozyme, karyological, osteological, and ethological research has been conducted on the charismatic Phrynocephalus of Central Asia (for a brief review on history of phylogenetic studies of the genus Phrynocephalus see Supplementary Text File 1). Regardless the phylogenetic and taxonomic relationships within the toad-headed agamas remain controversial and largely unresolved (e.g., Ananjeva \& Tuniyev 1992; Arnold 1999; Macey et al. 1993; Dunayev 1996; Golubev 1993; Zhao \& Adler 1993; Pang et al. 2003; Ananjeva et al. 2006; Solovyeva et al. 2011; Solovyeva et al.2012; and references therein). Hypothesis-testing can help deduce their origin, diversification and dispersal (Guo \& Wang 2007; Melville et al. 2009; Solovyeva et al. 2014). The most complete genealogic hypothesis obtained up to date (Solovyeva et al. 2014) is based entirely on the mtDNA data; several major nodes of the tree have little or no support, so elaboration of a more robust phylogeny based on nuclear markers is needed.

Herein, we explore a number of unresolved questions by using both mitochondrial and nuclear DNA markers based for 36 species of Phrynocephalus that cover the entire range of the genus. Specifically, we pursue three main objectives: (1) test the hypothesis that the nuDNA and mtDNA trees give compatible estimations of historical relationships; (2) evaluate hypotheses concerning potential climatic and tectonic drivers of speciation by using time-tree ages of each lineage calibrated based on molecular dating and fossils; and (3) reconstruct the ancestral distributions to differentiate among competing scenarios of historical biogeography. Our work offers the most complete taxon sampling to date by including up to $70 \%$ of the diversity of the genus. It helps to resolve longstanding phylogenetic and biogeographic issues of Central Eurasian biogeography and provides insights into the biogeographic consequences of Cenozoic aridization.

\section{Materials and methods}

\section{DNA samples}

We used 51 samples representing 33 nominal species of Phrynocephalus from the collection of Zoological Museum of Moscow University (ZMMU). The primary outgroup included six other Agaminae species from the genera Agama Daudin, 1802, Paralaudakia Baig, Wagner, Ananjeva \& Böhme, 2012, Stellagama Baig, Wagner, Ananjeva \& Böhme, 2012 and 
120 Trapelus Cuvier, 1817 (Supplementary Tables S1 and S2). For alcohol-preserved voucher

121 specimens, muscle tissue was removed and preserved in 96\% ethanol and stored subsequently at

$122-35^{\circ} \mathrm{C}$; three tissue samples were obtained from the dried skin of voucher specimens.

\section{DNA extraction, PCR conditions and sequencing}

Muscle and skin tissues were digested with Proteinase $\mathrm{K}$ and total genomic DNA was extracted using a standard phenol-chloroform extraction protocol followed with ethanol precipitation of DNA (Sambrook et al. 1989). Our analyses used the mitochondrial DNA dataset of Solovyeva et al. (2014), which included the following four mtDNA gene fragments: 654 bp of COI (cytochrome oxidase subunit I), 1053 bp of ND2 (NADH-dehydrogenase subunit II), 705 bp of ND4 (NADH-dehydrogenase subunit IV) and $297 \mathrm{bp}$ of $C y t b$ (cytochrome $b$ ). The total length of the concatenated mtDNA genes was 2703 bp (Supplementary Table S3). We also amplified exons of four nuclear DNA genes as follows: 1455 bp of $R A G-1$ (recombination activating gene), $675 \mathrm{bp}$ of $B D N F$ (brain derived neurotrophic factor), $1182 \mathrm{bp}$ of $A K A P 9$ (A-kinase anchor protein 9) and 876 bp of NKTR (natural killer-tumor recognition). The total length of these data was 4188 bp (Supplementary Table S3).

Primer pairs for PCR were taken from the literature (mtDNA: Ivanova et al. 2006; Wang Townsend et al. 2008; Townsend et al. 2011) or designed by us (Supplementary Table S4). PCR amplifications were performed in a reaction volume of $20 \mu \mathrm{l}$ containing ca. $100 \mathrm{ng}$ of template DNA, $0.3 \mathrm{pM} / \mu \mathrm{l}$ of each PCR primer, 1xTaq-buffer containing $25 \mathrm{mM} \mathrm{MgCl}_{2}$ (Silex, Moscow Russia), $0.2 \mathrm{mM}$ dNTPs, and 1 unit of Taq-polymerase (Silex, Moscow Russia; 5 units/ $\mu 1$ ). Protocols for PCR amplification were provided in the Supplementary Text File 2. PCR products were purified with alcohol precipitation and a PCR purification kit (Isogen, Moscow, Russia). Purified products were sequenced with both forward and reverse primers using ABI PRISM® BigDye $^{\mathrm{TM}}$ Terminator v.3.1 reagents and an Applied Biosystems 3730 DNA Analyzer (Applied Biosystems, Carlsbad, CA, USA). All sequencing followed the manufacturer's protocols as given in the Engelgart`s IMB RAN (Moscow, Russia). All unique sequences were deposited in GenBank (Supplementary Tables S1 and S2).

\section{Taxa selection and molecular data}

We added six sequences of Phrynocephalus available in GenBank to the final alignments 
151 phylogenetic inference and time-tree calibration. These included the following Near Eastern and

152 Middle Asian genera closely related to Phrynocephalus (Agaminae: Paralaudakia, Laudakia

153 Gray, 1845, Trapelus, Stellagama) as well as more distant Southeast Asian agamids (Draconinae:

154 Acanthosaura Gray, 1831, Draco Linnaeus, 1758, Calotes Daudin, 1802; Leiolepidinae:

155 Leiolepis Cuvier, 1829) and Australian taxa (Amphibolurinae: Moloch Gray, 1841, Pogona Storr, 156 1982, Chlamydosaurus Gray, 1825). The most distant outgroup taxa also included 157 representatives of Chamaeleonidae, Phrynosauridae, Dactyloidae, Iguanidae, Corytophanidae, 158 Tropiduridae, Polychrotidae, Leiocephalidae, Lacertidae, Opluridae, Crotaphytidae, including 159 representative taxa of the following agamid genera: Stellagama, Trapelus, Paralaudakia and 160 Agama for both nuclear and mtDNA dataset, and additionally representative taxa of the genera 161 Xenagama Boulenger, 1895, Laudakia, Bufoniceps Arnold, 1992, Pseudotrapelus Fitzinger, 1621843 and Calotes for the mtDNA dataset. Details on taxonomy, GenBank accession numbers and 163 associated references were summarized in Supplementary Tables S1 and S2.

\section{Phylogenetic inference}

Sequences were first aligned using the Clustal W algorithm (Thompson et al. 1994) in BioEdit Sequence Alignment Editor 7.1.3.0 (Hall 1999), with default parameters. Subsequently, the alignment was checked and manually revised if necessary using Seqman 5.06 (Burland 1999). Genetic distances were calculated using MEGA 6.1 (Tamura et al. 2013).

Phylogenetic tree reconstructions were performed with the following data sets: (1) each nuclear gene separately; (2) all nuclear genes concatenated; (3) all nuclear genes combined in a species tree estimation; (4) a concatenation of four mitochondrial genes as in Solovyeva et al. 1722014 but with the addition of P. rossikowi Nikolsky, 1898. To test whether the inclusion of distant outgroups can introduce any bias into results of tree inference, the nuclear and mitochondrial concatenations were put through an additional set of reconstructions omitting all non-agamid and non-agamine taxa, respectively. The optimum partitioning schemes for nuclear and mitochondrial alignments were identified with PartitionFinder (Lanfear et al. 2012) using greedy search algorithm under the AICc criterion.

Phylogenetic trees were reconstructed under the maximum likelihood (ML), maximum parsimony (MP) and Bayesian inference criteria. The ML trees were generated in Treefinder 180 v.March 2011 (Jobb 2011). For each subset, the best fitting substitution model was selected 
182 bootstrap replications (BSP) and expected likelihood weights (ELW). The unweighted MP 183 analyses were conducted in PAUP* v4.0b10 (Swofford 2002) with 1000 bootstrap replications. 184 Bayesian inference (BI) was performed in MrBayes v3.1.2 (Ronquist \& Huelsenbeck 2003) with 185 two simultaneous runs, each with four chains, for 200 million generations. We checked the 186 convergence of the runs and that the effective sample sizes (ESS) were all above 200 by exploring the likelihood plots using TRACER v1.5 (Rambaut \& Drummond 2007). The initial 10\% of trees were discarded as burn-in. Confidence in tree topology was assessed by posterior probability (BPP) (Huelsenbeck \& Ronquist 2001). four independent nuclear loci. Prior to the analysis, the molecular clock assumption was tested separately for each exon by hierarchical likelihood ratio tests using PAML v4.7 (Yang 2007). Following the results of these tests, we used a strict clock model for BDNF and uncorrelated lognormal relaxed clock models for the other three loci. No calibration information was utilized; the clock rate for $B D N F$ was set to one. We used the same models and partitioning scheme as in the ML analysis. A Yule prior for the species-tree shape and the piecewise constant population size model were assumed. Default priors were used for all other parameters. Two runs of 500 million generations were conducted in BEAST v1.8.0 (Drummond et al. 2012). Parameter convergence was assessed in Tracer; the first $10 \%$ of generations were discarded as the burn-in. TreeAnnotator v1.8.0 (part of the BEAST package) was used to generate the maximum clade credibility tree.

Partition homogeneity test (Farris et al. 1994; Farris et al.1995) as implemented in PAUP* v4.0b10 (Swofford 2002) was used to ensure the absence of significant conflict among the four nuclear datasets $(\mathrm{p}$-value $=0.071)$. We a priori regarded tree nodes with BSP values $75 \%$ or greater and BPP values over 0.95 as sufficiently resolved (Felsenstein 2004; Huelsenbeck \& Hillis 1993). BSP values between 75\% and 50\% (BPP between 0.95 and 0.90 ) were regarded as tendencies and below 50\% (BPP below 0.90) were considered to be not well-supported.

\section{Congruence between nuclear and matrilineal genealogy}

We tested if the mitochondrial genealogy of Solovyeva et al. (2014) was compatible with our nuDNA phylogeny to eliminate the possibility of mito-nuclear discordance and an introgressed mitogenome. ML trees with unconstrained and alternative constrained topologies were generated for the mitochondrial and nuclear datasets by using Treefinder v.March 2011. 
213 Treefinder was also used to calculate site-wise log-likelihoods and to perform the approximately 214 unbiased tree-selection test (AU; Shimodaira 2002). Significant discordance would have 215 precluded a total evidence approach that evaluated together the mtDNA and nuDNA datasets

216 because we wanted to differentiate between the initial cladogenic event(s) and the timing of 217 interspecific hybridization(s), if present.

\section{Divergence time estimates}

The mtDNA dataset of Solovyeva et al. (2014) and our nuDNA concatenation were used to define divergence times in BEAST v1.8.0 (Drummond et al. 2012). Site and clock models were set as in the species tree reconstruction. Analyses were run for 100 million of generations and the Yule model was set as the tree prior. Because no reliable paleontological data have been reported for Phrynocephalus, we used ten fossils from non-Agamid outgroup taxa and outgroup Agamidae as calibration points (see Supplementary Table S5, Supplementary Fig. S1).

\section{Area delimitation and biogeographic reconstruction}

We used the ML of Lagrange (Ree et al. 2005; Ree \& Smith 2008) to reconstruct the biogeographic history of Phrynocephalus. Transitions between discrete states (ranges) along tree branches were modeled as a function of time, thus enabling ML estimation of the ancestral states at cladogenic events. Lagrange found the most likely ancestral areas at a node, the split of the areas in the two descendant lineages, and calculated the probabilities of these most likely areas at each node (Ree \& Smith 2008). We defined seven regions for the analyses: Kazakhstan, North Caspian and Ciscaucasian deserts (KZ), Central Asia (CA), Minor Asia and Transcaucasia (MI), Tibet (TI), Turan (TU), Middle East (ME), and Near East and Arabia (AR) (for details on biogeographic regions definition and references see Supplementary Text File 3). The maximum number of regions included in one area was limited to two. We set two periods of time: before 10 Ma and after $10 \mathrm{Ma}$. This date echoed the considerable uplifting of the Pamir, Tianshan and Karakoram mountains. (Abdrakhmatov et al. 1996). The matrices of the modern distribution areas were given in Supplementary Table S6.

We reconstructed ancestral substrate niche evolution in Phrynocephalus under the maximum parsimony criterion using MPRsets command in PAUP* v4.0b10 (Swofford 2002) based on nuDNA topology with outgroup taxa included or excluded from the analysis.

242 Polytomies in the nuDNA-based tree were resolved in accordance with the mtDNA topology. To account for topological uncertainty, the analysis was repeated based on a tree sample (180) from 
244 the posterior distribution produced by BEAST. Substrate niche was coded using six character 245 states: (1) loose sand dunes; (2) fixed sands mixed with clay or gravel; (3) gravel and stone 246 deserts; (4) clay soils and salines; (5) clay soils mixed with gravel; and (6) large rocks and cliffs. 247 Transitions between states were formalized using step-matrix (Supplementary Table S7).

248 To examine the evolution of body size in Agaminae, we used weighted squared-change 249 parsimony (Maddison 1991) as implemented in Mesquite v3.31 (Maddison \& Maddison 2017). 250 We tested maximum SVL of taxa reported in literature or based on examination of voucher 251 specimens. Maximum SVLs for each taxon were provided in Supplementary Table S6.

252

253

254

255

256

257

258

259

260

261

262

263

264

265

266

267

268

269

270

271

272

\section{Results}

\section{Taxon sampling, data collection and sequence characteristics}

The complete, aligned matrix contained 38 samples of Phrynocephalus for mtDNA and 39 samples for nuDNA, representing 33 of the ca. 40 currently recognized species (Barabanov \& Ananjeva 2007; Uetz \& Hosek 2016). The concatenated aligned mtDNA dataset encompassed $2703 \mathrm{bp}$ and the nuDNA dataset $1488 \mathrm{bp}$. Information on the length of the fragments and variability were given in Supplementary Table S3. Uncorrected mtDNA genetic distances within Phrynocephalus were given in Table 1 (below diagonal).

\section{Phylogenetic inference from mtDNA}

Analyses of the mtDNA data resulted in the majority of nodes receiving high BSP and BPP support. Topological patterns were in general congruent across analyses and the results of Solovyeva et al. (2014). The ML tree is shown in Fig. 2. The result appeared to be insensitive to exclusion/inclusion of distant non-agamid and non-agamine outgroups (see Supplementary Figs. S2-S3).

Phrynocephalus was unambiguously monophyletic in all analyses (Fig. 2). Several nodes in the mitochondrial tree appeared insufficiently resolved. Nevertheless all species of Phrynocephalus were consistently assigned to one of the ten strongly supported matrilines (for their distribution see Supplementary Fig. S4):

(1) Subgenus Microphynocephalus, joining the small-sized, sand-dwelling Phrynocephalus from Middle Asia and the Middle East (Fig. 2; lineage A). 
273

274

275

276

277

278

279

280

281

282

283

284

285

286

287

288

289

290

291

292

293

294

295

296

297

298

299

300

301

302

(2) Subgenus Phrynosaurus represented by P. scutellatus from Iranian Plateau (Fig. 2, lineage B).

(3) Near and Middle East Phrynocephalus: P. arabicus Anderson, 1894 and P. maculatus Anderson, 1872 (Fig. 2; lineage C), with the latter species being paraphyletic with respect to the former.

(4) Subgenus Megalochilus Eichwald, 1831, including the large-sized, sand-dwelling $P$. mystaceus (Pallas, 1776) from Middle Asia (Fig. 2, lineage D).

(5) Subgenus Oreosaura joining viviparous Tibetan species (Fig. 2, lineage E).

(6) Middle Asian sun-watchers encompassing P. helioscopus and allied taxa (Fig. 2, lineage F; helioscopus-group).

(7) Southern Middle Asian (Turan) P. raddei (Boettger, 1889), P. ocellatus, P. rossikowi and P. strauchi Nikolsky, 1899 (Fig. 2, lineage G; raddei-group). P. rossikowi was omitted in the earlier mtDNA study of Solovyeva et al. (2014); our data strongly support its placement within the $P$. raddei species group.

(8) Tibetan oviparous $P$. axillaris Blanford, 1875 (Fig. 2, lineage H).

(9) P. versicolor species complex, inhabiting northern plains of Central Asia (Fig. 2, lineage I; versicolor-group). The versicolor-group had two sublineages: P. hispidus Bedriaga, 1909 from Mongolian Dzungaria and Phrynocephalus sp. 1 from Gansu; and $P$. przewalskii Strauch, $1876+$ P. frontalis Strauch, $1876+$ P. versicolor from central China and Mongolia joined with P. kulagini Bedriaga, 1909 from Tuva Republic (Russia).

(10) P. guttatus species complex, widespread in plains of Kazakhstan and northern Caspian region (Fig. 2, lineage J; guttatus-group). Within the guttatus-group, P. guttatus, P. alpherakii Bedriaga, 1905 and P. moltschanovi Nikolsky, 1913 clustered together.

\section{Phylogenetic inference from nuDNA and Mito-nuclear discordance}

ML, MP and BI analyses of the concatenated nuclear DNA dataset resulted in highly congruent trees (Fig. 3). Exclusion of non-agamid taxa did not change the topology significantly (Supplementary Fig. S5). Phylogenetic trees resulted from separate analyses of individual genes were shown in Supplementary Figs. S6-S9; values of AU-tests for nuDNA genes compatibility were given in Supplementary Table S8. The topology of the *BEAST species-tree for Phrynocephalus and the levels of nodal support (Fig. 4) coincided with the concatenated nuDNA 
303

304

305

306

307

308

309

310

311

312

313

314

315

316

317

318

319

320

321

322

323

324

325

326

327

328

329

330

331

332

333

dataset tree (Fig. 3) and were in good correspondence with the topologies from three of the four nuDNA genes (NKTR, RAG-1 and $A K A P 9)$.

Monophyly of Phrynocephalus received high support as did several species-groups: Microphrynocephalus (Fig. 3, lineage A: 99/100/1), Arabian species-group (Fig. 3, lineage C: 100/100/1), Megalochilus (Fig. 3, lineage D: 100/100/1), Oreosaura (Fig. 3, lineage E: 100/100/1) and P. raddei species-group (Fig. 3, lineage G: 95/84/1). The P. heliosopus-group obtained low support (Fig. 3, lineage F: -///0.89), but high support in the species-tree (Supplementary Fig. S4). Monophyly of the clade containing the $P$. guttatus- and P. versicolorgroups was highly supported (Fig. 3, lineages I, J: 100/99/1), but interrelationships within this clade remained unresolved. The $P$. versicolor-group was paraphyletic with respect to the $P$. guttatus-group, though with some support only from ELW (Fig. 3: 90/-/-).

The nuDNA phylogeny of Phrynocephalus conflicted significantly ( $<0.05$; AU) from the matrilineal genealogy. The nuDNA topology depicted three main clades (Fig. 3): (1) Microphrynocephalus, P. scutellatus, Arabian species-group and Megalochilus (clades A-D; 99/96/1); (2) Oreosaura (Clade E; 100/100/1); and (3) all other Phrynocephalus (clades F-J; 100/99/1). Most notably, the placements of Megalochilus and Oreosaura differed in important ways. Matrilineally, Oreosaura and Megalochilus aligned with Middle and Central Asian "core Phrynocephalus" with strong support (99/88/1.0). In contrast, the nuDNA biparental phylogeny united Megalochilus with Arabian and Iranian species (75/90/0.99), including the P. arabicusgroup, P. scutellatus and Microphrynocephalus with Oreosaura forming a sister-group to clades A-D. Other notable conflicts also occurred. The nuclear phylogeny did not depict a shared heritage for P. scutellatus and the Arabian species-group (Fig. 3), as did the mtDNA genealogy, but rather P. scutellatus (Clade B) was the sister-lineage of Microphrynocephalus (Fig. 2). The phylogenetic position of $P$. strauchi was contentious; analyses of the nuDNA dataset did not group it with the mtDNA raddei-group. Similarly, the phylogeny placed $P$. axillaris as a sisterlineage of the P. guttatus-versicolor-group (Figs. 3, 4, Supplementary Fig. S5; 95/91/1), but its matrilineal relationships were unresolved (Fig. 2).

We performed additional AU tree-selection test to test for significant differences between matrilineal genealogy and the nuclear phylogeny, including whether one or both datasets rejected alternative placements of particular clades. The test evaluated the conflicting positions of $P$. mystaceus, P. strauchi, P. scutellatus, Oreosaura, the basal position of Arabian species and 
334 Arabian species + Microphrynocephalus. The matrilineal genealogy was forced to the nuclear

335 dataset and vice versa. AU indexes for the basal position of Arabian species or Arabian species + 336 P. scutellatus in the matrilineal genealogy were not statistically rejected by nuclear markers $(\mathrm{p}=$ $3370.217, \mathrm{p}=0.277$, respectively). The alternative nuclear hypotheses for the clades $\mathrm{A}-\mathrm{E}$ and $\mathrm{D}-\mathrm{H}$ 338 were not rejected by mitochondrial data. The matrilineal position of $P$. mystaceus within the 339 lineage (Helioscopus + P. axillaris + P. mystaceus $)$ was rejected by nuclear markers $(\mathrm{p}=0.000)$, 340 and vice versa mitochondrial markers rejected the nuDNA resolution of $P$. mystaceus + Arabian 341 species + Microphrynocephalus + P. scutellatus $(\mathrm{p}=0.000)$. The AU test for P. strauchi 342 occurring within the raddei-lineage was not rejected statistically by nuclear data $(\mathrm{p}=0.752)$ and 343 the mitochondrial data did not reject the nuDNA resolution of $P$. strauchi + helioscopus-group (p $344=0.857)$. Existence of the matriline Oreosaura + "guttatus" + "versicolor" was rejected 345 according to nuclear data $(\mathrm{p}=0.000)$ and vice versa the mitochondrial dataset rejected position 346 of Oreosaura within A-E $(\mathrm{p}=0.000)$. Finally, we tested topologies of trees based on each 347 nuclear marker against final topology. The $B D N F$ dataset rejected the topology. In contrast, 348 original $R A G-1$ topology was rejected. P-values of the AU-tests of alternative topologies were 349 summarized in Supplementary Table S9. \\ 350 Divergence times and rates of change}

Chronograms from mtDNA and nuDNA data were presented in Supplementary Figs. S10

352

353

354

355

356

357

358

359

360

361

362

363

364 and S11, respectively. Timing of the internal nodes was summarized in detail in Supplementary Table S10. Estimated node-ages and the 95\% highest posterior density (95\% HPD) for the main nodes were detailed in Supplementary Table S10. The mtDNA dataset provided older estimates of ages as compared to nuDNA. All analyses proposed that the ancestor of Phrynocephalus originated between the end of Oligocene and beginning of the Miocene (mtDNA: 33.2 Ma (26.439.7); nuDNA: 26.9 Ma (22.6-31.7)) and the basal radiation dated to the Middle Miocene (mtDNA: 19.3 Ma (14.9-23.5); nuDNA 14.8 Ma (12.0-17.5)).

LTT plots gave a graphical representation of lineage-accumulation (Supplementary Fig. S12). The mtDNA (Fig. S12A) and nuDNA (Fig. S12B) plots had similar shapes that were best described as being anti-sigmoidal characterized by three periods of constant rate. The first rate constant was separated from the second by a plateau and occurred before $14 \mathrm{Ma}$ for mtDNA and before $11 \mathrm{Ma}$ for nuDNA and the second plateau occurred after these dates. The third period started after $5 \mathrm{Ma}$, followed by a slight rate-shift in both plots. 
365

366

367

368

369

370

371

372

373

374

375

376

377

378

379

380

381

382

383

384

385

386

387

388

389

390

391

392

393

394

\section{Ancestral area, substrate niche and body size evolution modeling}

The ancestral areas and biogeographic processes (vicariance, dispersal and colonization routes) reconstructed from nuDNA data were shown in Fig. 5. The most likely biogeographic scenario suggested that the Middle East plus the Turan area (ME-TU) was the most probable ancestral area for Phrynocephalus, thus supporting the hypothesis of a southern origin. Paleogeography of central Eurasia in Miocene-Pliocene was shown in Fig. 6.

Results of habitat evolution modelling for Phrynocephalus were given in Fig. 7. All simulations of the possible evolution of substrate niches in Phrynocephalus suggested that the most likely substrate type for the ancestor consisted of soft substrate, i.e. loose sands with nondifferentiated proluvial sediments, such as clay or gravel.

Results of ancestral state reconstructions of maximum SVL evolution for each taxon were shown in Fig. 8. Accordingly, the common ancestor of Phrynocephalus was likely significantly smaller (size category $87-97 \mathrm{~mm}$ ) than its sister taxa Laudakia, Stellagama and Paralaudakia (ancestral size category 147-157 mm). Most species of Phrynocephalus have been found to be smaller than their common ancestor (size categories 47-77 mm); however, several lineages of Phrynocephalus have subsequently increased their body size (P. maculatus: 87-97 mm; $P$. mystaceus: 77-127 mm), while further miniaturization was suggested for the P. interscapularisgroup (37-47 mm).

\section{Discussion}

\section{Phylogenetic relationships of Phrynocephalus}

Supplementary Text File 1 provides a brief review on history of phylogenetic studies of the genus Phrynocephalus.

Phylogenetic placement of Phrynocephalus. Our results are in accordance with previous studies on the higher phylogenetic relationships within the subfamily Agaminae (Macey et al. 2000; Guo et al. 2007; Melville et al. 2009) (Figs. 2 and 3). Sand-dwelling Bufoniceps laungwalaensis (Sharma 1978) from the Thar Desert of India, which was originally described as a species of Phrynocephalus (Sharma 1978), is the sister-lineage of the Middle Eastern-Middle Asian genus Trapelus; this corresponds with results of Macey et al. (2006) and Melville et al. (2009). The clade (Phrynocephalus + Laudakia s.1.) is poorly resolved; the old age of this 
395

396

397

398

399

400

401

402

403

404

405

406

407

408

409

410

411

412

413

414

415

416

417

418

419

420

421

422

423

424

425

radiation, which we estimate as early to mid-Oligocene (Supplementary Figs. S10, S11), likely complicates phylogenetic resolution. Future genome-scale studies are likely to recover these relationships. Regardless, the monophyly of Phrynocephalus (excluding Bufoniceps laungwalaensis) is unambiguous in all analyses.

Phylogenetic relationships within Phrynocephalus. Analyses of nuclear gene exons (Fig. 3) resolve the phylogenetic relationships for most of the species-groups revealed by the matrilineal genealogy (Fig. 2), including the following: P. interscapularis-group (subgenus Microphrynocephalus; lineage A on mtDNA-genealogy), subgenus Oreosaura (lineage E), $P$. guttatus- and $P$. versicolor-groups (lineages $\mathrm{J}$ and $\mathrm{I}$, respectively), P. mystaceus (subgenus Megalochilus; lineage D), P. helioscopus (lineage F) and P. arabicus-P. maculatus (lineage C). The P. guttatus- and P. versicolor-matrilines are sister-groups, although concatenated analyses of nuDNA data nest the former within the latter (Fig. 3) and the species-tree suggests sister-group relationships (Fig. 4). These are the youngest associations within Phrynocephalus. MtDNA analyses resolve close relationships between the $P$. helioscopus-group and $P$. axillaris, but analyses of nuDNA data resolve $P$. helioscopus-lineage $+P$. ocellatus-lineage with strong support and place $P$. axillaris as the sister clade to the $P$. guttatus $+P$. versicolor lineages.

Overall, the nuDNA phylogenetic trees are generally better resolved and show higher nodal support values than the mtDNA trees. The nuDNA phylogeny also shows higher congruence with traditional systematics of the genus. Owing to biparental inheritance, we prefer the nuDNA topology as the phylogeny of the genus Phrynocephalus (Fig. 3), which coincides well with the species-tree (Fig. 4). Further, the matrilineal genealogy appears to resolve the introgression of mitogenomes via interspecific hybridization (below). In general, Phrynocephalus has three main clades, but the relationships among them are not well-supported.

Clade I (Fig. 4) contains the P. interscapularis-group (subgenus Microphrynocephalus), P. arabicus-P. maculatus-group, P. scutellatus and P. mystaceus (subgenus Megalochilus). The phylogenetic relationships between these four groups are essentially unresolved. This groups includes oviparous species inhabiting Arabia, Near to Middle East and Middle Asia. Many of them associate with sand dunes. Monophyly of the $P$. arabicus-maculatus group and Microphrynocephalus (P. interscapularis-P. ornatus Boulenger, 1887 -group) has strong support. Clade II (Fig. 4) includes viviparous species inhabiting high elevations of the QTP (subgenus Oreosaura). Phylogenetic relationships within this group remain unresolved with the 
426 exception of a sister-species relationship between $P$. theobaldi Blyth, 1863 and $P$. forsythii 427 Anderson, 1872. In the concatenated analysis of nuDNA exons (Fig. 3), monophyly of the group 428 that includes Clade I and Clade II receives strong support (75/90/0.99), although this node does 429 not receive high support in the species-tree analysis (Fig. 4).

430 Clade III (Fig. 4), the "core" Phrynocephalus, contains all remaining taxa of the genus 431 and consists of oviparous lowland species inhabiting arid areas of Central and Middle Asia and 432 the Middle East. It includes two strongly supported groups: $P$. helioscopus-P. raddei and $P$. 433 guttatus $-P$. versicolor. Monophyly of the $P$. helioscopus species complex and the $P$. ocellatus $-P$. 434 raddei-group receives strong support. The phylogenetic position of $P$. strauchi remains 435 unresolved, while $P$. axillaris appears as the sister-taxon of the $P$. guttatus- $P$. versicolor-group, 436 which coincides with morphology; P. axillaris and members of the P. guttatus-P. versicolor 437 species complexes share a number of morphological similarities, including having bright axillary 438 spots possibly used in signaling communication (Fig. 3).

439 Our phylogeny has better resolution and wider taxon sampling than previously published 440 mtDNA-based genealogies (Pang et al. 2003; Guo et al. 2007; Melville et al. 2009; Solovyeva et 441 al. 2014) and the nuDNA-based phylogeny (1200 bp fragment of RAG-1) of Melville et al. 442 (2009). Our tree also differs from the morphological phylogeny of Arnold (1999), in which the 443 Tibetan viviparous Oreosaura appear to be deeply nested within the core clade of 444 Phrynocephalus and nests with the P. helioscopus-group, while P. mystaceus, P. arabicus, $P$. longicaudatus Haas, 1957 (as P. maculatus) and Microphrynocephalus occupy the basal position in the Phrynocephalus radiation. The potential explanation of these differences may be connected with habitat preferences; adaptation to types of substrate may drive convergent changes and morphology. Both Tibetan viviparous Oreosaura and P. helioscopus-group members occur mostly on solid (rocky or clay) substrates and are superficially similar in external morphology, sharing robust body habitus, shortened tail and other features. At the same time, sand-dwelling Microphrynocephalus, P. mystaceus and P. arabicus and Bufoniceps share such characters as presence of enlarged scale fringes on toes, enlarged or keeled scales on throat, eyelids or jaws, flattened body and tail, which are considered to be adaptive for life on large wind-blown sand dunes. Arnold (1999) rooted his tree with Trapelus and Bufoniceps. However,

455 convergent similarity between send-dwelling Phrynocephalus and Bufoniceps potentially could 456 lead to the basal position of $P$. mystaceus. 

mt- and nuDNA trees is the positions of $P$. mystaceus: the nuDNA-based topology strongly suggests that $P$. mystaceus as a sister-group with respect to the Middle-Eastern $P$. interscapularis-group (Microphrynocephalus), P. scutellatus and the Arabian P. arabicus-P.

461 maculatus-group (Fig. 3). In contrast, the mtDNA genealogy unambiguously places $P$. mystaceus within core Phrynocephalus with P. axillaris being a possible sister-lineage (Fig. 2). The AU tests either rejects or do not provide statistical support for genomic compatibility (except as noted above; Supplementary Table S8). Mitochondrial and nuclear genetic markers have yielded many conflicting geographic patterns (reviewed by Toes \& Brelsford 2012). Examples of mitonuclear discordance in reptiles remain limited (McGuire et al. 2007; Zarza et al. 2011; Pedall et al. 2010; Renoult et al. 2009; Leache \& Cole 2007; Ng \& Glor 2011; Nguyen et al. 2017), perhaps because the discrepancy is rarely tested. Different mechanisms and rates of evolution for mt- and nuDNA may account for some observed topologic discrepancies. Fisher-Reid and Wiens (2011) evaluated 14 vertebrate clades for which both mtDNA and nuDNA data exist and reported that $30-60 \%$ of the nodes differed between trees from the two genomes. The results of our AU-tests suggest that topological differences between mtDNA and nuDNA hypotheses can be statistically significant. Thus, our analyses suggest that the combining of data from the two genomes should be avoided or done with caution without first testing for compatibility. Equally important, analyses based on combined datasets may hide biogeographic histories of studied taxa due to gene sorting, genetic recombination and gene flow of nuDNA (Nguyen et al. 2017).

Several processes, including incomplete lineage sorting or introgressive hybridization, may best explain mito-nuclear discordance (Toes \& Brelsford 2012). The deep divergence between P. mystaceus and core Phrynocephalus, as well as the unique morphology of this largesized species differing from any other congener (Fig. 3), renders incomplete lineage sorting an unlikely scenario (McGuire et al. 2007). Thus, in case of P. mystaceus, an ancient introgression of mitochondrial genome due to interspecific hybridization best explains the discordance. According to mtDNA time-tree (Supplementary Fig. S10) divergence between mitochondrial genomes of ancestral P. mystaceus and P. axillaris took place in late Miocene (around 10.4 Ma), whereas the basal differentiation of Phrynocephalus is estimated as the middle Miocene (around 14.8 Ma; Supplementary Fig. S11) according to nuDNA data. Hence, the possible hybridization between $P$. mystaceus and $P$. axillaris ancestors occurred approximately $5 \mathrm{Ma}$ after speciation, 
488 and this roughly corresponds to the level of divergence within the present-day $P$. guttatus $-P$. 489 versicolor species complexes. This timing makes interspecific hybridization possible. Further, 490 male-biased dispersal favors mitochondrial genome introgression (Toes \& Brelsford 2012) and 491 Phrynocephalus appears to have male-mediated gene flow. Discordant breaks in mtDNA and 492 nuDNA markers occur in at least for four species: P. vlangalii-P. putjatai Bedriaga, 1909-groups 493 (Noble et al. 2010; Qi et al. 2013), and in the P. przewalskii-P. frontalis-groups (Uruquhart et al. 494 2009). Other lineages may have the same pattern. Phrynocephalus mystaceus is the largest 495 species of the genus and it shows adaptations typical of a psammophilous lifestyle including 496 triangular scales forming fringes on toes, ridged subdigital lamellae, distinctly flattened body and 497 tail, and a pair of unique cutaneous flaps at mouth corners with numerous spiny scales along flap 498 edges. Similar spiny scales can occur in mouth corners of miniaturized psammophilous members 499 of the P. interscapularis-group and P. euptilopus Alcock et Finn, "1896” 1897. These species are 500 similar to P. mystaceus and occur in the Middle East and Middle Asia. Thus, our nuDNA 501 phylogenetic hypothesis corresponds with life history, biogeographic and morphological 502

503

504

505

506

507

508

509

510

511

512

513

514

515

516

517

518 similarities between P. mystaceus and smaller psammophilous taxa of Phrynocephalus.

\section{Taxonomic implications}

The results of our phylogenetic analyses require some taxonomic changes within Phrynocephalus. These include recommendations on genus- and species-level taxonomy.

Generic taxonomy of Phrynocephalus. The significant morphological diversity of Phrynocephalus has been reflected in their generic taxonomy. First, Eichwald (1831) proposed the new name Megalochilus for the largest species of the genus, P. mystaceus. Ananjeva (1987) recognized the genus, but this was not accepted by subsequent researchers (e.g. Zhao \& Adler 1993; Dunayev 1996; Arnold 1999). Sharma (1978) described P. laungwalaensis from Rajasthan (India), but Arnold (1992) removed it from Phrynocephalus and reassigned it to monotypic Bufoniceps, which he treated as a sister-clade of Phrynocephalus, Subsequent molecular analyses supported this arrangement (Macey et al. 2006; Melville et al. 2009). Based on the phylogenetic analysis by Pang et al. (2003), Barabanov and Ananjeva (2007) suggested recognizing the Tibetan viviparous species-group as subgenus Oreosaura. Because the phylogenetic relationships within oviparous species remained largely unknown, this subgeneric taxonomy was not largely accepted. Solovyeva et al. (2014) analyzed four mtDNA gene fragments and the morphological data of Arnold (1999) and suggested that small-bodied sand-dwelling 
519 Phrynocephalus, including the $P$. interscapularis-group and $P$. ornatus, constituted a 520 morphologically and phylogenetically distinct group; they erected new subgenus 521 Microphrynocephalus for it. However, our nuDNA-based phylogeny requires reconsideration of 522 this arrangement.

523 Excluding Bufoniceps laungwalaensis, nuDNA, mtDNA (herein) and morphological 524 (Arnold 1999) analyses indicate monophyly of Phrynocephalus. Thus, the splitting of 525 Phrynocephalus into several genera is inadvisable. Further molecular studies are necessary to 526 test for monophyly of Laudakia s.l. and its relationships with respect to Phrynocephalus.

527 The recognition of subgenera within Phrynocephalus is a matter of taste. The genus has 528 three clearly defined clades that may warrant taxonomic recognition. The largest of these clades, 529 or the "core" Phrynocephalus (Clade III, Fig. 4), encompasses the majority of oviparous species 530 and corresponds to the nominative subgenus Phrynocephalus s.s. Clade II (Fig. 4) unites 531 viviparous species of the QTP and is well-defined by morphology and life history traits; 532 subgenus Oreosaura applies to it. Last, Clade I (Fig. 4) joins a number of species from Arabia, 533 Middle East and Middle Asia that have plesiomorphic character states (Arnold (1999), including 534 the $P$. arabicus $-P$. maculatus-group, $P$. interscapularis- $P$. ornatus-group, $P$. scutellatus and $P$. 535 mystaceus. The $P$. interscapularis $-P$. ornatus-group, which was erected as subgenus 536 Microphrynocephalus Dunayev, Solovyeva, Poyarkov, 2014 (Solovyeva et al. 2014) are 537 miniaturized species adapted to life in aeolian sand habitat and they share a number of 538 morphological synapomorphies (Arnold 1999) and geographic coherence. The older name 539 Phrynosaurus Fitzinger, 1843 is available. However, the phylogenetic position of its type 540 species - $P$. olivieri Duméril et Bibron, 1837, which is now considered as a junior synonym of $P$. 541 scutellatus (Olivier) — within the clade remains unclear. Finally, P. mystaceus, to which the name 542 Megalochilus Eichwald, 1831, is available, forms a sister-group with respect to all other 543 members of Clade I. This species has a unique morphology and evolutionary history, which 544 likely includes an episode of ancient intraspecific hybridization with introgression of its 545 mitochondrial genome from Clade III species.

546 Two alternative taxonomic decisions are possible: recognizing the whole of Clade I as 547 Megalochilus, or splitting it into a number of smaller taxa, including Megalochilus, 548 Phrynosaurus, Microphrynocepahlus and an unnamed taxon for the P. arabicus-P. maculatus 549 species group. Our analyses lack samples from a number of Middle Eastern species, which likely 
550 fall into Clade I, including $P$. ornatus ornatus, $P$. clarkorum Anderson et Leviton, 1967, $P$. 551 lutensis Kamali \& Anderson, 2015, P. luteoguttatus Boulenger, 1887 and, most importantly, 552 large-sized and psammophilous P. euptilopus. Accordingly, we suggest that further taxon 553 sampling and additional nuDNA-markers be evaluated before making subgeneric changes in the 554 interest of maintaining taxonomy stability.

555 Taxonomic differentiation within species complexes. Our results indicate that in many cases

556 the currently adopted taxonomy is incomplete and does not reflect the actual biodiversity within 557 Phrynocephalus. We briefly review these cases and provide corresponding taxonomic 558 recommendations.

559

560

Lineage A. Microphrynocephalus. This group of miniaturized species inhabit wind561 blown sands of southern Middle Asia (Turan) and Middle East. Our analyses include $P$. 562 interscapularis, P. sogdianus Chernov, 1948 and P. ornatus vindumi Golubev, 1998 only. Although unsampled, P. ornatus ornatus, P. clarkorum, P. luteoguttatus, P. lutensis most likely belong to this group based on morphological characters (Arnold 1999; Kamali \& Anderson 2015). Phrynocephalus sogdianus was described from southern-most Tajikistan by Chernov (1948) as a subspecies of $P$. interscapularis (type locality "vicinity of the Pyandzh [= Panj] village"). Later, Sokolovsky (1975) raised it to be a full species. Our locality for P. sogdianus, Kurjalakum Sands, occurs approximately $50 \mathrm{~km}$ from the type locality and the Vakhsh River Valley separates it from the type locality. Our substantial divergence in mtDNA sequences (uncorrected genetic $p$-distance $=3.9-4.3 \%$ for $C O I$ ) coincides with morphological and distributional differences and favors the recognition of $P$. sogdianus as a full species. species, which inhabits clay or gravel deserts on the Iranian Plateau, remains unclear within Clade I. The recent molecular study of Rahiamian et al. (2015) identified at least four highly divergent matrilines in southern and north-eastern Iran. Thus, P. scutellatus might consist of a species complex that requires reconsideration. inhabits aeolian sand dunes from the Arabian Peninsula to westernmost Iran, and P. maculatus, 579 which occurs on hard substrates and has two presently recognized subspecies: P. m. maculatus 580 (Anderson) from the Iranian Plateau and P. m. longicaudatus from the Arabian Peninsula. Our 
581 sampling lacks $P$. golubewii Shenbrot et Semenov, 1990 from Turkmenistan and P. sakoi 582 Melnikov, Melnikova, Nazarov, Al-Johany \& Ananjeva, 2015 from Oman. Melnikov et al. (2014) 583 revised P. arabicus complex, considered P. nejdensis Haas, 1957 and P. macropeltis Haas, 1957 584 as valid species, and described the population of $P$. arabicus s.1. from western Iran as the new 585 species P. ahvazicus Melnikov, Melnikova, Nazarov, Rajabizadeh, Al-Johany, Amr \& Ananjeva, 586 2014. However, this taxonomic action was based primarily on small to moderate genetic 587 distances between these forms ( $p$-distance 2.7\%-6.0\%) and differences observed in coloration of 588 living animals. Because Melnikov et al. (2014) did not include many morphological and meristic 589 characters that serve to diagnose the species, these data must be taken with caution (Kamali \& 590 Anderson 2015). Our sample from western Iran corresponds to P. ahvazicus of Melnikov et al. 591 (2014). However, we tentatively assign it as $P$. arabicus s.l. pending a further re-assessment of 592 the taxonomy of the P. arabicus species complex. Previously, Solovyeva et al. (2014) suggested 593 that paraphyly of $P$. maculatus s.l. occurred with respect to $P$. arabicus. Our multilocus nuDNA594 based phylogeny agrees with the matrilineal genealogy and indicates that $P$. longicaudatus from 595 the Arabian Peninsula is a sister-taxon of $P$. arabicus ( $p$-distance $=8.0 \%$ for $C O I$ ). This differs 596 from $P$. maculatus from Iran being reconstructed as a sister-taxon to the clade joining $P$. 597 arabicus and $P$. longicaudatus. Based on the principle of monophyly, as well as genetic and 598 distributional differences, we raise P. longicaudatus to full species status as Phrynocephalus 599 longicaudatus (Haas 1957) comb. et stat. nov.

600 Lineage D. Megalochilus. Phrynocephalus mystaceus represents a widespread species601 complex that inhabits wind-blown sands and large sand dunes from north-eastern Iran to the 602 Turan region, Middle Asia and the Caspian Basin. While intraspecific taxonomy within $P$. 603 mystaceus is in a state of flux, we report on two highly divergent lineages within this complex 604 that were firstly revealed by mtDNA sequences (Solovyeva et al. 2014; $p$-distance $=6.3-6.5 \%$ 605 for COI). Nuclear markers also reveal deep divergence between these two lineages, one of which 606 is restricted to East Khorasan Province, Iran (P. mystaceus 2) and another occupies the rest of 607 species range in Middle Asia (P. mystaceus 1). Thus, the taxonomy of this complex requires 608 further study.

609 Lineage E. Oreosaura. This clade consists of viviparous highland species inhabiting 610 deserts of the QTP and our analyses evaluate P. erythrurus, P. forsythii, P. putjatai, P. vlangalii, 611 and $P$. theobaldi within the complex. The phylogenetic relationships among these species remain 
612 essentially unresolved. Pang et al. (2003), Jin et al. (2008; 2017), Jin \& Liu (2010), Noble et al. 613 (2010) and Zhang et al. (2010) assessed their phylogenetic relationships and biogeography.

614 Lineage F. P. helioscopus-P. persicus-group. This group, which was until recently 615 considered to be a widespread polytypic species $P$. helioscopus s.l., occurs in the montane 616 deserts from western and northern Iran, Transcaucasia, the Turan Region and Middle Asia to the 617 Caspian Basin in the west and westernmost China and Mongolia in the east. Phrynocephalus 618 helioscopus has a robust, tuberculate morphology and inhabits mostly hard substrates in clay or 619 clay/gravel deserts. Previous phylogenetic analyses of mtDNA $(C O I)$ and nuDNA (interSINE620 PCR) by Solovyeva et al. (2011) indicated the presence of two main clades within this complex: 621 P. helioscopus complex (Middle Asia and adjacent territories) and P. persicus De Filippi, 1863 622 complex (Iran and Transcaucasia), both of which contained a number of highly divergent 623 lineages. Subsequent analysis of morphological characters resulted in recognizing seven 624 subspecies within P. helioscopus and three within P. persicus (Solovyeva et al. 2012). Our 625 phylogeny does not support monophyly of the P. helioscopus + P. persicus group (Fig. 2), 626 although the species-tree does (Fig. 4). The P. helioscopus complex is a monophyletic unit. Deep 627 divergences in both mtDNA and nuDNA genes occur between P. saidalievi Sattorov, 1981 from 628 Ferghana Valley, Uzbekistan and Tajikistan and P. h. helioscopus + P. h. varius Eichwald, 1831 $629(p=12.0-12.6 \%$ in COI). Eremchenko \& Panfilov (1999) proposed full species status for $P$. 630 saidalievi based on differences in karyotype and our analyses strongly support this arrangement. 631 Based on the principle of monophyly, along with the molecular and morphological analyses of 632 Solovyeva et al. (2011; 2012), we also recognize Phrynocephalus meridionalis Dunayev, 633 Solovyeva, Poyarkov in Solovyeva, 2012 comb. et stat. nov. This species is the sister-taxon of $P$. 634 saidalievi and was originally described as a subspecies of $P$. helioscopus from the Surkhandarya 635 Region of southern Tajikistan. The species differs markedly in its mtDNA sequences $(p=10.0-$ $63610.6 \%$ in COI), nuclear markers and morphology (Solovyeva et al. 2011; Solovyeva et al. 2012). 637 Future studies can address further taxonomic reassignments within the $P$. helioscopus and $P$. 638 persicus complexes.

639 Lineage G. $P$. raddei-P. ocellatus group. This group contains a number of species that 640 have comparatively small distributions involving gravel or clay-gravel deserts of Turkmenistan, 641 Uzbekistan and eastern Tajikistan. Unfortunately, we were unable to obtain nuDNA sequences 642 from our sample of $P$. rossikowi due to poor quality of the DNA from this sample; however, our 
$643 \mathrm{mtDNA}$ analysis strongly suggests that $P$. rossikowi is a member of this species group, and this is 644 concordant with morphological similarity and ecology of this species, which prefer solid 645 substrates (salines) (Solovyeva 2017). Until recently, with the exception of P. rossikowi, two 646 species were recognized: P. raddei Boettger, 1888 (subspecies $P$. raddei raddei Boettger, 1888 647 from Turkmenistan and P. raddei boettgeri Bedriaga, 1905 from Uzbekistan) and P. reticulatus 648 Eichwald, 1831 (subspecies P. re. reticulatus Eichwald, 1831 from Uzbekistan, P. re. bannikovi 649 Darevsky, Rustamov et Shammakov, 1976 from Turkmenistan and P. re. strauchi from Ferghana 650 Valley in Uzbekistan and Tajikistan; Terentjev \& Chernov 1949; Wermuth 1969, Bannikov et al. 651 1977; Barabanov \& Ananjeva 2007). Barabanov \& Ananjeva (2007) considered P. boettgeri a 652 junior synonym of P. raddei. Golubev (1991) examined the type specimens of Agama ocellata 653 Lichtenstein in Eversmann, 1823 and demonstrated that it was the senior synonym of $P$. 654 reticulatus Eichwald, 1831, which he considered as a subjective junior synonym of the former. 655 Subsequently, the name P. ocellatus (Lichtenstein in Eversmann, 1823) was widely accepted for 656 over 25 years (e.g. Dunayev 1996; Dunayev 2007; Golubev et al. 1995; Manilo 2000, 2001; 657 Manilo \& Golubev 1993; Szczerbak 1994; Solovyeva et al. 2014). Despite that, Barabanov \& 658 Ananjeva (2007: 56) proposed to protect the name $P$. re. reticulatus and in doing so violated the 659 principle of priority (ICZN 1999). Herein, we follow Golubev (1991) and use the name $P$. 660 ocellatus in order to maintain nomenclatural stability and priority.

661 Our mtDNA analyses suggest monophyly of the P. raddei boettgeri-P. ocellatus group 662 and suggest that P. strauchi is their sister-group. Their relationships within Phrynocephalus 663 remain unresolved (Fig. 2). Concatenated (Fig. 3) and species-tree (Fig. 4) analyses of nuclear 664 loci resolve paraphyly within the group. The phylogenetic position of $P$. strauchi is unresolved 665 and $P$. raddei boettgeri-P. ocellatus form a well-supported sister-group relationships with $P$. 666 helioscopus-P. persicus (lineage F). This clearly supports giving full-species status of $P$. 667 strauchi as suggested by Dunayev (1995). Our sampling within this group is incomplete because 668 we lack P. bannikovi and P. raddei raddei from Turkmenistan. Further studies are required to 669 clarify phylogenetic relationships within this group.

670 Lineage H. $\boldsymbol{P}$. axillaris. Oviparous $P$. axillaris from sand deserts of Taklimakan and 671 adjacent parts of western China is a highly divergent lineage according to our concatenated (Fig. 672 3) and species-tree (Fig. 4) analyses of nuDNA-markers. It is the sister-taxon of lineages I-J (P. 673 guttatus $-P$. versicolor-group). These lizards have a slender habitus, share habitat preferences and 
674 have bright red to blue axillary spots used in intraspecific communication (Fig. 3). Zhang et al. 675 (2010) reported on the phylogeography of this species.

676 Lineages I-J. P. guttatus-P. versicolor group. Analyses of both mtDNA (Fig. 2) and 677 nuDNA (Figs. 3 and 4) datasets suggest monophyly of the group. They are morphologically 678 diverse oviparous species from lowland deserts of northern Middle and Central Asia. While 679 analyses of the mtDNA data indicate reciprocal monophyly of $P$. guttatus and P. versicolor 680 lineages, analyses of nuDNA data nest latter within the former. The P. guttatus-group (lineage J) 681 inhabits various types of deserts ranging from sand dunes to gravel deserts. They occur in the 682 Middle Asia from Caspian Basin to the westernmost China. Dunayev $(1996 ; 2009)$ assessed the 683 taxonomy and distribution of lizards in Kazakhstan. NuDNA sequences fail to resolve 684 relationships within this complex, yet mtDNA markers suggest the presence of three main 685 matrilines: (1) P. guttatus, P. moltschanovi and P. alpheraki from the Caspian and Aral basins 686 and Ili Depression in eastern Kazakhstan; (2) P. kuschakewitschi Bedriaga, 1905 and P. incertus 687 Bedriaga, 1905 from the Balkhash Lake Basin in eastern Kazakhstan; and (3) P. melanurus from 688 the Zaysan Depression in northeastern Kazakhstan and Junggar Depression of northwestern 689 China. Significant differentiation in mtDNA sequences ( $p=4.0-7.9 \%$ for $C O I)$, morphology and 690 distribution argue for recognizing these forms of $P$. guttatus as full species. However, further 691 research including more variable nuclear DNA-markers is necessary before doing so, especially 692 in the Balkash Lake Basin in Eastern Kazakhstan, which cradles the highest species diversity of 693 this group and where gene flow between species might take place (Solovyeva et al., in prep.).

694 Lineage I comprises the species of $P$. versicolor-group that inhabit lowland deserts of 695 northern Central Asia. Whereas the nuDNA analyses do not resolve relationships within this 696 group, mtDNA results suggest the presence of two matrilines, one containing populations from 697 the Mongolian part of the Junggar Depression (Mongolian Jungaria), previously assigned to $P$. 698 versicolor hispida (Orlova et al. 2014). Concatenated analysis of nuDNA loci suggest its 699 recognition as the full species Phrynocephalus hispidus Bedriaga, 1909 comb. et stat. nov. The 700 mtDNA divergence of this lineage from other members of $P$. versicolor group is substantial $(p=$ 701 6.7-7.3\%). Our analyses are in concordance the previous results by Gozdzik \& Fu (2009) and 702 Urquhart et al. (2009) on genetic uniformity of P. przewalskii and P. frontalis. Despite the 703 presence of two matrilines, the nuDNA markers do not differ between the two and 704 Phrynocephalus przewalskii Strauch, 1876 appears to be the senior synonym for this taxon. 
Phrynocephalus versicolor is a wide-ranging species that inhabits the Mongolian and 706 Chinese Gobi Desert as far northwards as the Tuva Republic in southern Siberia (Russia). 707 Traditionally, two subspecies were recognized: P. v. kulagini from Tuva and northern Mongolia 708 and $P$. v. versicolor from the rest of species' range. Previous studies (Wang \& Fu 2004) did not 709 include samples of P. v. kulagini; our analyses strongly indicate paraphyly of P. versicolor s.l. 710 with specimens from Tuva being significantly differentiated both in mtDNA $(p=5.18 \%-5.37 \%$ 711 for COI), nuDNA genes, and morphology. These results are supported by morphological 712 differentiation (Dunayev 2009), and this requires recognition of the full species Phrynocephalus 713 kulagini Bedriaga, 1909 comb. et. stat. nov.

\section{Implications for morphological and ecological evolution}

Ancestral structural substrate niche. A debate exists on the ancestral habitat niche of likely adapted to soft, wind-blown sand dunes (Chernov 1948; Whiteman 1978; Arnold 1999), whereas others argued that the group arose in stony or clay deserts with solid ground (Ananjeva \& Tuniyev 1992, Golubev 1989). Arnold (1999) provided a morphology-based phylogeny for Phrynocephalus, and with Trapelus and Bufoniceps reconstructed as its sister-taxa. He assumed that this group of genera demonstrated a gradual adaptation to soft substrates, such as loose aeolian sand-dunes.

We reconstructed the evolution of the preferred habitat types among all sampled Phrynocephalus and Agaminae outgroups using MP (Fig. 7, Supplementary Table S6). Most Agaminae genera climb to some extent (Arnold 1999) as Agama, Pseudotrapelus and Laudakia s.l. exhibit. These taxa are found mostly frequently on large rocks and boulders, and this also occurs for most Trapelus, which inhabit sandy or gravel deserts, but eagerly climb bushes and trees. Only three genera-Xenagama, Bufoniceps and Phrynocephalus-are strictly grounddwelling, and this appears to be the derived condition. Our analysis suggests that two lineages within Agaminae independently adapted to life on soft substrates: the common ancestor of Trapelus and Bufoniceps, and the ancestor of Phrynocephalus.

Loose sands with non-differentiated proluvial sediments appear to be the ancestral habitat of Phrynocephalus. This initial adaptation could result in evolution of a set of advantageous features typical for this genus, such as (1) skin covering the tympanum, (2) lateral fringes of elongate scales on digits and eyelids, (3) countersunk jaws, (4) flattened body and tail and (5) a 
736 characteristic burial behavior by lateral oscillations of the body (Arnold 1999; Dunayev 1996).

737 Further differentiation within Phrynocephalus likely led to adaptations of different lineages to

738 contrasting habitat preferences. Phrynocephalus of Clade I mostly specialize for life on sandy

739 habitats such as large, wind-blown dunes (P. mystaceus and P. ornatus-P. interscapularis

740 groups). Two species of Clade I (P. scutellatus and P. maculatus) demark independent shifts to

741 firmer ground (clay soils with gravel or salines). Clade II demonstrates adaptation to high

742 elevation, stony or gravel deserts; a reversal to sand habitats occurs for $P$. forsythii, which

743 inhabits the sandy Taklimakan Desert at lower elevations. Clade III likely had a sand-dwelling

744 ancestor (Fig. 7). Many species in this group live on fixed sands with patches of gravel or clay,

745 or they can be observed on various substrates. Some species switch to wind-blown dunes $(P$.

746 axillaris, P. melanurus, P. przewalskii) or gravel (P. alpherakii, P. kuschakewitschii, $P$.

747 melanurus, $P$. versicolor, $P$. strauchi). All members of the $P$. raddei-P. helioscopus group are

748 specialized to life on hard substrates (clay, gravel, salines) and show no reversal to sand habitats,

749 with the exception of $P$. helioscopus varius, which occurs in sandy areas of pine forests in the

750 northernmost limit of its distribution in the Altai Region of Russia (Kotlov 2008).

751 Body size evolution. Phrynocephalus show significant variation in body size ranging

752 from 35-37 mm (P. ornatus vindumi) to $123 \mathrm{~mm}$ (P. mystaceus) (Supplementary Table S6). The

753 weighted squared-change parsimony algorithm serves to reconstruct the evolution of maximum

754 SVL in Phrynocephalus and outgroup Agaminae (Fig. 8). Accordingly, rock-dwelling or

755 climbing forms such as Agama, Trapelus and Laudakia s.l. have larger SVLs than strictly

756 ground-dwelling Bufoniceps, Xenagama and Phrynocephalus. Body size decreases early in the

757 history of Phrynocephalus, suggesting that initial miniaturization of its common ancestor was

758 advantageous in wind-blown sand habitats. Strict sand-dwellers, Microphrynocepahlus (P.

759 ornatus $-P$. interscapularis group) found in the aeolian sand dunes of the Middle East and Turan

760 are the most miniaturized group of Phrynocephalus $\left(\mathrm{SVL}_{\max }<47 \mathrm{~mm}\right)$. An example of an overt

761 reversal in body size occurs in P. mystaceus, which is the largest member of the genus and is also

762 specialized to large floating sand dunes. Similar change in body size possibly took place in

763 psammophilous $P$. euptilopus, which appears to be closely related to $P$. interscapularis-P.

764 luteoguttatus, but is much larger $\left(\mathrm{SVL}_{\max } 63 \mathrm{~mm}\right)$ (Alcock \& Finn 1897; Arnold 1999). Some

765 species adapted to hard substrates also show an increase in body size, such as $P$. maculatus

$766 \quad\left(\mathrm{SVL}_{\max } 91 \mathrm{~mm}\right)$ and P. putjatai $\left(\mathrm{SVL}_{\max } 84 \mathrm{~mm}\right)$. 
767 Historical biogeography

768 Time-tree and origin of Phrynocephalus. Estimates of divergence and diversification 769 times for Phrynocephalus vary among authors. Macey et al. (1993) based on allozymes assumed 770 that Phrynocepalus represented an ancient radiation and diverged about $35 \mathrm{Ma}$. According to 771 immunological data, Ananjeva and Sokolova (1990) estimated the divergence of Phrynocephalus 772 from other Agaminae took place around $11 \mathrm{Ma}$, while their allozyme data provided an estimate 773 of 6 Ma. Using relaxed clock dating, Guo and Wang (2007) suggested a mid-Miocene origin 774 (13.87 Ma, 95\% CI 8.5-20.5). Estimates by Melville et al. (2009) were older and varied for 775 mtDNA and nuDNA datasets. Their mtDNA suggested all Phrynocephalus including $P$. 776 interscapularis diverged 28.9 Ma (21.1-36.2 Ma). Excluding P. interscapularis, the estimated 777 origin dated to $22.4 \mathrm{Ma}(16.5-30.6 \mathrm{Ma})$ for mtDNA, and 15.8 Ma (11.8-23.0 Ma) for nuDNA.

778 Our analyses based on mtDNA data suggest that the ancestor of Phrynocephalus diverged 779 from other Agaminae in early Oligocene around 33.2 Ma (19.92-45.69 Ma), or based on nuDNA 780 data in late Oligocene around 26.9 Ma (22.44-31.27 Ma). The basal differentiation within the 781 genus took place in early Miocene (mean 19.3 Ma; 95\% CI 12.20-28.90 Ma) or mid-Miocene 782 (mean 14.76 Ma; 95\% CI 12.01-17.47 Ma) based on mtDNA and nuDNA data, respectively 783 (Supplementary Table S10). Due to absence of a reliable fossil record of Phrynocephalus, all of 784 our calibration nodes correspond to relatively old splits between outgroup taxa, which can 785 potentially result in biased date estimates (see, e.g. Brochu 2004; Hugall et al. 2007).

786 Our estimates best fit the results of Melville et al. (2009), but are slightly younger. 787 Melville et al. (2009) used one biogeographic and four fossil calibrations, including the 788 enigmatic Bharatagama from Early-Middle Jurassic of peninsular India, which is interpreted as 789 a putative stem acrodont (Evans et al. 2002). However, the attribution of this fossil is 790 questionable (Townsend et al. 2011) and our calibration scheme does not include it 791 (Supplementary Table S5).

792

Biogeographic history of Phrynocephalus and Cenozoic climate change. 793 Phrynocephalus is a characteristic element of the deserts of Palearctic Asia, and there is a 794 substantial sympatry between species and species groups (Arnold 1999) (Supplementary Fig. S4). 795 Several hypotheses have been invoked to explain the current broad distribution of the genus. 796 Nikolsky (1916) assumed a Central Asian or Tibetan origin based on remarkable morphological 797 diversity of Central Asian species ("northern origin" hypothesis). Ananjeva and Tuniyev (1992) 
798 speculated that there were two original centers for the species of Phrynocephalus in the former 799 USSR: Central Asia in the north and Middle Asia in the south. However, their complex 800 hypothesis is not based on an estimated phylogeny and it omits numerous species of 801 Phrynocephalus unique to Southwest Asia and China (Kamali \& Anderson 2015). Macey et al. 802 (1993) suggested that the origins of Phrynocephalus trace back to Indian collision with Eurasia 80335 Ma. Later Arnold (1999) suggested that Phrynocephalus evolved in the southern margins of 804 the present distribution, i.e. in the Arabia-NW India area rather than in Central Asia ("southern 805 origin" hypothesis). Some researchers (Wang \& Macey 1993; Zeng et al. 1997; Pang et al. 2003) 806 argued that the basal differentiation of Phrynocephalus and the origin of the viviparous species 807 group resulted from vicariance associated with the uplifting of the QTP. Guo and Wang (2007) 808 suggested that Phrynocephalus diversified in the Late Miocene to Pleistocene from centers of 809 origin in temperate deserts of Central Asia, and the Tarim and Junggar basins. Several rapid 810 speciation events followed this in a relatively short time (northern origin hypothesis). However, 811 despite recent progress based on molecular phylogenetics (Pang et al. 2003; Melville et al. 2009; 812 Guo \& Wang 2007), our understanding of the biogeography of Phrynocephalus, especially of the 813 oviparous taxa inhabiting Middle Asia and South-Western Asia, remains very poor.

814 Phrynocephalus belongs to the subfamily Agaminae, which is hypothesized to have 815 originated in Afro-Arabia and colonized Eurasia during a slow closure of the Tethys following 816 movement of Arabian plate northwards (Macey et al. 2000). The landbridge connecting Afro817 Arabia with Eurasia (known as "Gomphotherium-landbridge" or GLB; Figs. 5 and 6) was formed 818 around 18-17 Ma and it facilitated a great faunal exchange between these landmasses (Rögl 819 1998; Rögl 1999). After a temporary disruption, the landbridge has persisted continuously since 820 the mid-Miocene about 15 Ma (Harzhauser 2007; Pook et al. 2009; Metallinou et al. 2012; 821 Scherler et al. 2013; Šmíd et al. 2013). Our analyses strongly suggest that the ancestor of 822 Phrynocephalus diverged from other agamines around $27 \mathrm{Ma}$ in late Oligocene, or ca. 9-10 823 million years predating the first connection of Afro-Arabia with Eurasia. Because Asian 824 agamines are not monophyletic with respect to African taxa, if Macey et al.'s $(2000 ; 2006)$ 825 hypothesis on an Afro-Arabian origin of the subfamily is correct, then the ancestor of 826 Phrynocephalus, Laudakia and Trapelus + Bufoniceps should have colonized Asia 827 independently from Arabia before formation of the GLB. Because Agamidae and putative 828 Agaminae were present in Asia starting from the Late Cretaceous and early Cenozoic (Estes 
829 1983; Borsuk-Białynicka \& Moody 1984; Alifanov 1989; Borsuk-Białynicka 1996; Prasad \& 830 Bajpaj 2008), we cannot exclude an Asian origin of Agaminae with subsequent colonization of 831 Africa. The oldest known fossil of Phrynocephalus is reported from eastern Turkey (Zerova \& 832 Chkhikvadze 1984); this record is quite young quite young (ca. $5 \mathrm{Ma}$ ) and not reliable. The 833 driver of the basal differentiation within Agaminae in Oligocene (ca. $29 \mathrm{Ma}$ ) remains an enigma, 834 as does the distribution of the common ancestor of Phrynocephalus (Fig. 5).

835 Figure 5 shows the main events in biogeographic history of Phrynocephalus inferred 836 from molecular analyses and paleorange reconstructions. The basal radiation of Phrynocephalus 837 happened around 14.8 Ma and likely took place in Middle East or southern Middle Asia (Turan) 838 (Fig. 5). This scenario cannot reject the "southern origin" hypothesis for Phrynocephalus, as it 839 does for the other hypotheses.

840 One of the most remarkable episodes of global climate evolution during the Cenozoic is 841 the Middle Miocene Climatic Transition (MMCT), which occurred between 14.8 and 14.1 Ma. 842 (Flower \& Kennett 1994). At that time, a major and permanent cooling trend replaced the warm 843 and humid tropical or subtropical climate of the Mid-Miocene Thermal Optimum (17-15 Ma; 844 Zachos et al. 2001; Böhme 2003). The MMCT saw an increased meridional temperature gradient 845 that strengthened the boundaries between climatic zones and increased aridification of the mid846 latitudes (Flower \& Kennett 1994). The MMCT was synchronous with the Paratethys salinity 847 crisis (Rögl 1999), which was a major drying of the Paratethys Sea that may have formed 848 significant wind-blown sand and evaporitic desert areas in Middle Asia. The MMCT 849 aridification trend facilitated the spread of drier landscapes over the Mediterranean Basin, Arabia, 850 the Iranian Plateau and Middle Asia and promoted dispersal of xerophilic species (Manafzadeh 851 et al. 2014). The basal radiation of Phrynocephalus into clades I-III coincides perfectly with 852 onset of the MMCT (14.8 Ma). The increasing aridification provided a diversity of desert 853 habitats for Phrynocephalus to occupy as they started to disperse out of the ancestral area in 854 Middle East and Turan (Fig. 5). A similar pattern was recently shown for agamid fan-throated 855 lizards (genus Sitana Cuvier, 1829), which diversified in response to ongoing aridification of the 856 Indian subcontinent in the late Miocene (Deepak \& Karanth 2018).

857 The ancestors of viviparous Oreosaura (Clade II) supposedly colonized the QTP 13.5858 10.0 Ma and diversification within this clade began around 3.8 Ma ago (Figs. 5 and 6). Our 859 estimated divergence for Oreosaura is older than the earlier estimate of $9.7 \mathrm{Ma}$ (95\% interval: 
$8607.2-13.0 \mathrm{Ma}$ ) by Jin and Brown (2013). Our date coincides with hypothesized major uplifting of 861 the QTP (Shackleton \& Chang 1988) and, thus, is consistent with the view that viviparity 862 evolved when this clade became restricted to regions of high elevation. The orogenesis of Tibet 863 is traditionally regarded as the main driving force of Asian monsoons system and subsequent 864 cooling and progressive aridization in Central Asia (Ramstein et al. 1997). However, recent 865 works raise a doubt on the Miocene uplifting of the QTP, suggesting that Tibet has been 4-5 km 866 high since the mid-Eocene (ca. $40 \mathrm{Ma}$ ), while Indian and Southeast Asian summer monsoons, 867 and Central Asian winter monsoons arose at different times and are unrelated to Tibetan 868 orogenesis (reviewed by Renner 2016). These new data necessitate significant reconsideration of 869 QTP historical biogeography and Phrynocephalus may represent a promising model group for 870 such studies.

871 Oviparous clades I and III remained largely within the hypothetical ancestral range of 872 Phrynocephalus (Middle East and Turan) (Fig. 5 and 6). Clade I has its highest diversity in the 873 Iranian Plateau and adjacent parts of the Middle East. The ancestor of P. mystaceus diverged 874 around 11.3 Ma; this large-sized psammophilous species spread northwards to Turan, Middle 875 Asia and the Caspian Basin where vast areas of wind-blown sand deserts were formed after 876 gradual drying up of the Paratethys Sea. Simultaneously, an ancestor of the P. arabicus-P. 877 maculatus group occupied deserts of the Arabian Peninsula between 10 and 5 Ma (Fig. 5). The 878 vicariant divergence between the ancestor of $P$. arabicus $+P$. longicaudatus from the Near East 879 and Iranian P. maculatus happened around 4.8 Ma. This coincides with intensive uplifting of the 880 Zagros Mountains in western Iran around 7 to $5 \mathrm{Ma}$ ago (Moutherau et al. 2012).

881 Oviparous clade III encompasses the highest number of species and has the largest 882 distribution in ranging from the Middle East and Asia Minor to Turan and Middle and Central Asia. Cladogenesis started in the Late Miocene (ca. 8.9-7.1 Ma) and was likely influenced by 884 progressive aridification of central Eurasia, orogenesis and changes in level of the Paratethys Sea. The age of the Central Asian deserts is questionable. The $22 \mathrm{Ma}$ estimation of the onset of aridification in northwestern China (Xia \& Hu 1993; Guo et al. 2002) corresponds with estimates 887 for the basal radiation in Dipodidae (Shenbrot et al. 2017), which is the major autochthonous 888 component of Central Asian desert mammal community. The primary center of radiation for 889 Phrynocephalus in Southwest Asia best explains their apparent lag in radiation. 
The $P$. raddei-P. helioscopus group adapted to life on gravel or clay deserts. The highest 891 diversity within this group occurs on alluvial plains of Middle Asia and Turan. The $P$.

892

893

894

895

896

897

898

899

900

901

902

903

904

905

906

907

908

909

910

911

912

913

914

915

916

917

918

919

920

helioscopus-P. persicus species complex has largest distribution penetrating westwards to Transcaucasia and eastern Asia Minor, and northwards to the Caspian Basin, lowland deserts of Middle and Central Asia as far as western Mongolia (Fig. 5). Orogenetic processes in the Iranian Plateau and Kopet Dagh Mountains (Smit et al. 2013) possibly shaped the initial splits (6.2-3.4 Ma). The common ancestor of the $P$. axillaris and $P$. guttatus $-P$. versicolor group likely dispersed to Central Asia around 8.5 to $7 \mathrm{Ma}$, where it diversified. Accordingly, $P$. axillaris appears to have remained in the Taklimakan Basin and adjacent parts of Tibet, where desertification started from at least 22.6 Ma ago (Zheng et al. 2015). The ancestors of the $P$. guttatus-P. versicolor group penetrated to Middle Asia (Dunayev 2009). Divergence between $P$. guttatus and P. versicolor species complexes occurred around $3.8 \mathrm{Ma}$, and this may coincide with accelerated uplifting of the Altai and Tianshan mountains around 5.0 to 3.1 Ma (Avouac et al. 1993; Abdrakhmatov et al. 1996; Charreau et al. 2005; Yuan et al. 2006). The ancestors of $P$. guttatus and P. moltschanovi further spread westwards, occupying the Caspian Basin and northwestern Turan (Fig. 5).

Plio-Pleistocene glacial cycling likely profoundly affected subsequent radiations and range expansions within species complexes occupying northern parts of Middle and Central Asia (Aubekerov \& Gorbunov 1999). Formation of local montane glaciers or permafrost areas during glacial maximums could have led to the retreat of Phrynocephalus to warmer refugia followed by subsequent dispersals in warmer periods (Melville et al. 2009). Apparently, the QTP, now home to an impressive radiation of viviparous Oreosaura, was covered by a thick ice sheet in the Pleistocene (Kuhle 1998). Hence, their distributions and the role they played in shaping the Central Asian biota remains insufficiently understood and requires further studies.

\section{Conclusions}

Exhaustive taxonomic sampling of Phrynocephalus is challenging. Some species of Phrynocephalus are only known from the type specimens and old collections (e.g. P. euptilopus and P. nasatus) (Barabanov \& Ananjeva 2005), while others occur in politically unstable zones (e.g. deserts of Pakistan, Afghanistan, and Taklamakan). Our analyses provide the most comprehensive taxonomic and gene sampling for Phrynocephalus to date. We evaluate 32 
921 nominal taxa using four mtDNA and four nuDNA protein-coding genes. The sampling comprises

922 over four-fifths of the species and covers the distribution of the genus. The mtDNA and nuDNA 923 trees clarify the initial cladogenesis of these lizards. Statistically significant mito-nuclear 924 discordance occurs likely due to hybridization and the introgression of mitogenomes. Analyses 925 shed light on a number of taxonomic issues. Our results contribute to the interpretation of 926 diversification patterns of Central Asian arid zone lizards and provides insights into the historical 927 biogeography of this region.

928 Analyses confirm the monophyly of Phrynocephalus and infer its biogeographic history. 929 The ancestral area of the Agaminae and factors that influenced its diversification remains 930 uncertain. The origin of Phrynocephalus dates to the Late Oligocene (26.9 Ma) and this precedes 931 the formation of the Mid-Miocene landbridge that connected Africa and Asia. The common 932 ancestor of Phrynocephalus appears to have been a ground-dwelling, miniaturized agamine 933 adapted to sand habitats. The basal divergence of Phrynocephalus into three major clades 934 appears to have occurred in the Middle East or southern Middle Asia (Turan) around 14.8 Ma. 935 This corresponds well with the Mid-Miocene Climatic Transition-climate cooling that 936 coincided with aridification and spreading of xerophytic plants across Mediterranean and 937 Paratethys Basins. Subsequent drying up of the Paratethys Sea formed vast desert habitats that 938 Phrynocephalus appears to have occupied. Two oviparous clades dispersed independently to 939 lowland deserts of the Arabian Peninsula, Middle and Central Asia. Orogenetic processes and 940 Paratethys Basin dynamics appear to have driven further cladogenesis, which Pliocene941 Pleistocene climate oscillations built upon. Substantial variation in body size and morphology 942 occurs in the oviparous lizards. Viviparous Oreosaura occupied the QTP around 13.5-10 Ma. 943 Cladogenesis in this group dates between the late Oligocene and mid-Pliocene depending on the 944 dataset (3.8 Ma from nuDNA, 6.4 Ma from mtDNA). This estimate coincides well with the 945 divergence time of another viviparous group of lizards inhabiting Central Asia - the racerunner 946 subgenus Pareremias (Lacertidae) (Orlova et al. 2017), which was dated to about 6.3 Ma from 947 mtDNA data (Guo et al. 2011).

948 Climatic changes during the Cenozoic, including the ongoing aridification of central 949 Eurasia, shaped the biodiversity of the region (e.g., Peng et al. 2006; Yang et al. 2006; Jin et al. 950 2008; Melville et al. 2009; Guo et al. 2011; Jin \& Brown 2013; Pisano et al. 2015). Most recent 951 biogeographic studies assume the hypothesis that speciation in Central Asia correlated with the 
952 evolution of an East Asian monsoon climate triggered by the rapid uplifting of the QTP 953 (Harrison et al. 1992; Harrison et al. 1995; An et al. 2001; Molnar 2005). However, 954 biogeographic histories of many taxa, including those inhabiting Central Asia and the QTP, 955 might require reconsideration due to conflicting hypotheses on geological and climatic history of 956 the region (Renner 2016). Accordingly, our study highlights the importance of Cenozoic 957 paleogeographic and paleoclimatic events in the diversification of Palaearctic lizards.

958

\section{Acknowledgements}

960 The authors are grateful to the following colleagues who took part in the fieldwork, collected 961 material and discussed the results, assembled and facilitated obtaining samples, as well as 962 providing access to collections: V.F. Orlova, E.V. Vashetko, M.A. Chirikova, Weiwei Zhou, Wei 963 Gao, T.N. Duysebayeva, P.V. Kvartalnov, T.A. Nazhmudinov, M.N. Yakubov, L.A. Neymark, 964 A.A. Vedenin, I.V. Artyushin, and E.A. Peregontsev. NAP thanks Alexandra A. Elbakyan for 965 help with accessing required literature. 


\section{References}

968 Abdrakhmatov KY, Aldazhanov SA, Hager BH, Hamburger MW, Herring TA, Kalabaev KB,

969

970

971

972

973

974

975

976

977

978

979

980

981

982

983

984

985

986

987

988

989

990

991

992

993

994

995 Makarov VI, Molnar P, Panasyuk SV, Prilepin MT, Reilinger RE, Sadybakasov IS, Souter BJ, Trapeznikov YA, Tsurkov VY, Zubovich AV. 1996. Relatively recent construction of the Tien Shan inferred from GPS measurements of present day crustal deformation rates. Nature 384:450-453. https://doi.org/10.1038/384450a0

Alcock AW, Finn F. 1897. An account of the Reptilia collected by Dr. F.P. Maynard, Captain A.H. McMahon, C.I.E., and the members of the Afghan-Baluch Boundary Commission of 1896. Journal of the Asiatic Society of Bengal 65:550-566. [1896]

Alifanov VR. 1989. New Priscagamida [sic] (Lacertilia) from the Upper Cretaceous of Mongolia and their systematic position among Iguania. Paleontological Journal 1989: 68-80. [in Russian]

An Z, Kutzbach JE, Prell WL, Porter SC. 2001. Evolution of Asian monsoons and phased uplift of the Himalaya-Tibetan Plateau since late Miocene times. Nature 411:62-66. https://doi.org/10.1038/35075035

Ananjeva NB, Orlov NL, Khalikov RG, Darevsky IS, Ryabov SA, Barabanov AV. 2006. The Reptiles of Northern Eurasia. Pensoft Series Faunistica 245.

Ananjeva NB, Sokolova TM. 1990. The position of the genus Phrynocephalus Kaup 1825 in agamids system. Trudy Zoologicheskogo Instituta Akademii Nauk SSSR 207:12-21. [in Russian]

Ananjeva NB, Tuniev BS. 1992. Historical biogeography of the Phrynocephalus species of the USSR. Asiatic Herpetological Research 4:76-98.

Ananjeva NB. 1987. On the validity of Megalochilus mystaceus (Pallas, 1776). In: Ananjeva NB, Borkin LJ, Eds. Systematics and Ecology of Amphibians and Reptiles. Proceedings of the Zoological Institute USSR Academy of Sciences Leningrad 157:4-13. [in Russian]

Arévalo E, Davis SK, Sites JW Jr. 1994. Mitochondrial DNA sequence divergence and phylogenetic relationships among eight chromosome races of the Sceloporus grammicus complex (Phrynosomatidae) in central Mexico. Systematic Biology 43:387-418. https://doi.org/10.1093/sysbio/43.3.387 
996 997

998

999

1000

1001

1002

1003

1004

1005

1006

1007

1008

1009

1010

1011

1012

1013

1014

1015

1016

1017

1018

1019

1020

1021

1022

1023

Arnold EN. 1999. Phylogenetic relationships of toad-headed lizards (Phrynocephalus, Agamidae) based on morphology. Bulletin of the British Museum (Natural History), Zoology 65(1,3):1-13.

Arnold EN. 1992. The Radjasthan toad-headed lizard, Phrynocephalus longwalensis (Reptilia: Agamidae) represents a new genus. Journal of Herpetology 26:467-472.

Aubekerov B, Gorbunov A. 1999. Quaternary permafrost and mountain glaciation in Kazakhstan. Permafrost and Periglacial Processes 10:65-80.

Avouac J-P, Tapponnier P, Bai P, You M, Wang G. 1993. Active thrusting and folding along the northern Tien Shan and late Cenozoic rotation of the Tarim relative to Dzungaria and Kazakhstan. Journal of Geophysical Research 98:11791- 11808.

Bannikov AG, Darevsky IS, Ischchenko VG, Rustamov AK, Szczerbak NN. 1977. Opredelitel Zemnovodnikh i Presmikayushchikhsya Fauni SSSR [Guide to the Reptile and Amphibian Fauna of the USSR]. Enlightenment Publ., Moscow, USSR 414. [in Russian]

Barabanov AV, Ananjeva NB. 2007. Catalogue of the available scientific species-group names for lizards of the genus Phrynocephalus Kaup, 1825 (Reptilia, Sauria, Agamidae). Zootaxa 1399: 1-56. https://doi.org/10.11646/zootaxa.1399.1.1

Böhme M. 2003. The Miocene climatic optimum: evidence from ectothermic vertebrates of Central Europe. Palaeogeography, Palaeoclimatology, Palaeoecology 195:389-401. https://doi.org/10.1016/S0031-0182(03)00367-5

Borsuk-Białynicka M, \& Moody SM. 1984. Priscagaminae, a new subfamily of the Agamidae (Sauria) from the Late Cretaceous of the Gobi Desert. Acta Palaeontica Polonica 29:5181.

Borsuk-Białynicka M. 1996. The Late Cretaceous lizard Pleurodontagama and the origin of tooth permanency in Lepidosauria. Acta Palaeontologica Polonica 41(3):231-252.

Brochu CA. 2004. Calibration age and quartet divergence date estimation. Evolution 58(6):13751382.

Burland TG. 1999. DNASTAR's Lasergene Sequence Analysis Software. Methods in Molecular Biology 132:71-91. https://doi.org/10.1385/1-59259-192-2:71 
1024 Cerling TE, Harris JM, MacFadden BJ, Leakey MG, Quade J, Eisenmann V, Ehleringer JR.

1025

1026

1027

1028

1029

1030

1031

1032

1033

1034

1035

1036

1037

1038

1039

1040

1041

1042

1043

1044

1045

1046

1047

1048

1049

1050

1051

1052

1053

1997. Global vegetation change through the Miocene/Pliocene boundary. Nature 389:153-158. https://doi.org/10.1038/38229

Charreau J, Chen Y, Gilder S, Dominguez S, Avouac J-P, Sen S, Sun D, Li Y, Wang W-M. 2005. Magnetostratigraphy and rock magnetism of the Neogene Kuitun He section (northwest China): implications for Late Cenozoic uplift of the Tianshan Mountains. Earth and Planetary Science Letters 230:177-192. https://doi.org/10.1016/j.epsl.2004.11.002

Chernov SA. 1948. Reptiles - Reptilia. In: Pavlovsky EN, Vinogradova BS, Eds. The Animals of the USSR. Vol. 2. The desert zone. Published by USSR Academy of Sciences, Moscow-Leningrad 127-161. [in Russian].

Chernov SA. 1959. Reptilia. Fauna of Tajik USSR. Dushanbe 48:203. [in Russian]

Clemann N, Melville J, Ananjeva NB., Scroggie MP, Milto K, Kreuzberg E. 2008. Microhabitat occupation and functional morphology of four species of sympatric agamid lizards in the Kyzylkum Desert, central Uzbekistan. Animal Biodiversity and Conservation 31(2):1-12.

Deepak V, Karanth P. 2018. Aridification driven diversification of fan-throated lizards from the Indian subcontinent. Molecular Phylogenetics and Evolution 120(2018): 53-62. https://doi.org/10.1016/j.ympev.2017.11.016

Drummond AJ, Suchard MA, Xie D, Rambaut A. 2012. Bayesian phylogenetics with BEAUti and the BEAST 1.7. Molecular Biology and Evolution 29(8):1969-1973. https://doi.org/10.1093/molbev/mss075.

Dunayev EA. 1995. Reviewed description of the types of Phrynocephalus strauchi Nikolsky, 1899 (Squamata, Agamidae) and materials on the history of its study, distribution, and variability. Russian Journal of Herpetology 2(2):87-94.

Dunayev EA. 1996. On the possible use of the ethological features in the taxonomy and phylogeny of toad agamas. Russian Journal of Herpetology 3(1):32-38.

Dunayev EA. 1996. Nomenclature and distribution of toad-agamas, Phrynocephalus (Reptilia, Agamidae) in Iliyskaya Hollow. Bulletin of the Moscow Society of Naturalists, Biology Ser., Moscow 101(3):36-41. [in Russian]

Dunayev EA. 2007. Phylogeny of lizards of Phrynocephalus genus (Reptilia: Agamidae): history of study and methodic approaches. Voprosy Gerpetologii 105-114. [in Russian] 
1054 Dunayev EA. 2009. Systematics and paleogeography: conceptual synthesis by the example of

1055

1056

1057

1058

1059

1060

1061

1062

1063

1064

1065

1066

1067

1068

1069

1070

1071

1072

1073

1074

1075

1076

1077

1078

1079

1080

1081

1082

Phrynocephalus (superspecies guttatus) (Reptilia: Agamidae). In: Sviridov AV, Shatalkin AI, Eds. Evolution and Systematics: Lamarck and Darwin in modern studies. Archiver of the Zoological Museum of Moscow State University. Vol. L. Moscow: KMK scientific press 274-298. [in Russian]

Eichwald DE. 1831 Zoologia specialis quam expozitis animalibus tum vivis, tum fossilibus potissimus rossiae in universum, et poloniae in specie. Posterior, specialem expositionem Spondylozoorum continens. Vilnius 404.

Eremchenko V, Panfilov A. 1999. Some question of methodology of taxonomy and phylogeny of toad agamas on the example of Phrynocephalus helioscopus (Pallas, 1771) (Sauria: Agamidae). Nauka i Noviye Tekhnologii, Bishkek 3:116-122 [in Russian with English summary].

Estes R. 1983. Sauria Terrestria, Amphisbaenia (Handbuch der Paläoherpetologie, v. 10A). Stuttgart. Gustav Fischer Verlag: 249.

Evans SE, Prasad GVR, Manhas BK. 2002. Fossil lizards from the Jurassic Kota formation of India. Journal of Vertebrate Paleontology 22:299-312. https://doi.org/10.1671/02724634(2002)022[0299:FLFTJK]2.0.CO;2

Farris JD, Kallersjo M, Kluge AG, Bult C. 1994. Testing significance of incongruence. Cladistics 10:315-319. https://doi.org/10.1111/j.1096-0031.1994.tb00181.x

Farris JD, Kallersjo M, Kluge AG, Bult C. 1995. Constructing a significance test for incongruence. Systematic Biology 44:570-572. https://doi.org/10.1093/sysbio/44.4.570

Felsenstein J. 2004. Inferring phylogenies. Vol. 2. Sinauer Associates, Inc. Publishers, Sunderland, Massachusetts, $465 \mathrm{pp}$.

Fisher-Reid MC, Wiens JJ. 2011. What are the consequences of combining nuclear and mitochondrial data for phylogenetic analysis? Lessons from Plethodon salamanders and 13 other vertebrate clades. BMC Evolutionary Biology 11:300. https://doi.org/10.1186/1471-2148-11-300

Flower BP, Kennett JP. 1994. The Middle Miocene climatic transition: East Antarctic ice sheet development, deep ocean circulation and global carbon cycling. Palaeogeography, 
1083

1084

1085

1086

1087

1088

1089

1090

1091

1092

1093

1094

1095

1096

1097

1098

1099

1100

1101

1102

1103

1104

1105

1106

1107

1108

1109

1110

1111

1112

Palaeoclimatology, $\quad$ Palaeoecology $\quad$ 108:537-555. $\quad$ https://doi.org/10.1016/00310182(94)90251-8

Golonka J. 2004. Plate tectonic evolution of the southern margin of Eurasia in the Mesozoic and Cenozoic. Tectonophysics 381(1):235-273. https://doi.org/10.1016/j.tecto.2002.06.004

Golubev ML, Gorelov YK, Dunayev EA, Kotenko TI. 1995. On the finding of Phrynocephalus guttatus (Gmel.) (Sauria, Agamidae) in Turkmeniya and its taxonomic status. Bulletin of the Moscow Society of Naturalists [Bulleten Moskovskogo Obschestva Ispytateley Prirody], Otdel Biologicheskiy 100(3):31-39 [in Russian with English summary].

Golubev ML. 1991. About the name Agama ocellata Lichtenstein In Eversmann, 1823 (Reptilia, Agamidae) with redescription of the types. Herpetological Researches. Leningrad 1:1217. [in Russian]

Golubev ML. 1993. The variegated toad agama in Djungar Gate (Eastern Kazakstan) with notes on certain systematic problems of Phrynocephalus versicolor str. (Reptilia: Agamidae). Asiatic Herpetological Research 5:51-58.

Gozdzik A, Fu J. 2009. Are toad-headed lizards Phrynocephalus przewalskii and P. frontalis (family Agamidae) the same species? Defining species boundaries with morphological and molecular data. Russian Journal of Herpetology 16 (2):107-118.

Guo X, Dai X, Chen D, Papenfuss T, Ananjeva NB, Melnikov DA, Wang Y. 2011. Phylogeny and divergence times of some racerunner lizards (Lacertidae: Eremias) inferred from mitochondrial 16S rRNA gene segments. Molecular Phylogenetics and Evolution 61(2):400-412. https://doi.org/10.1016/j.ympev.2011.06.022

Guo X, Wang Y. 2007. Partitioned Bayesian analyses, dispersal-vicariance analysis, and the biogeography of Chinese toad-headed lizards (Agamidae: Phrynocephalus): a reevaluation. Molecular Phylogenetics and Evolution 45(2):643-662. https://doi.org/10.1016/j.ympev.2007.06.013

Guo ZT, Ruddiman WF, Hao QZ, Wu HB, Qiao YS, Zhu RX, Peng SZ, Wei JJ, Yuan BY, Liu TS. 2002. Onset of Asian desertification by 22 Myr ago inferred from loess deposits in China. Nature 416:159-163. https://doi.org/10.1038/416159a

Haas G. 1957. Some amphibians and reptiles from Arabia. Proceedings of the California Academy of Sciences 29(3):47-86. 
1113 Hall TA. 1999. BioEdit: a user-friendly biological sequence alignment editor and analysis program for Windows 95/98/NT. Nucleotide 41:95-98.

1115

1116

1117

1118

1119

1120

1121

1122

1123

1124

1125

1126

1127

1128

1129

1130

1131

1132

1133

1134

1135

1136

1137

1138

1139

1140

1141

Harrison TM, Copeland P, Kidd WSF, Loevera OM. 1995. Activation of the Nyainqentanghla shear zone: implications for uplift of the southern Tibetan Plateau. Tectonics 14:658-676. https://doi.org/10.1029/95TC00608

Harrison TM, Copeland P, Kidd WSF, Yin A. 1992. Raising Tibet. Science 255:1663-1670.

Harzhauser M, Kroh A, Mandic O, Piller WE, Göhlich U, Reuter M, Berning B. 2007. Biogeographic responses to geodynamics: a key study all around the Oligo-Miocene Tethyan Seaway. Zoologischer Anzeiger-A Journal of Comparative Zoology 246:241256. https://doi.org/10.1016/j.jcz.2007.05.001

Heled J, Drummond AJ. 2010. Bayesian inference of species trees from multilocus data. Molecular Biology and Evolution 27:570. https://doi.org/10.1093/molbev/msp274

Huelsenbeck JP, Hillis DM. 1993. Success of phylogenetic methods in the four-taxon case. Systematical Biology 42:247-264. https://doi.org/10.1093/sysbio/42.3.247

Hugall AF, Foster R, Lee MS. 2007. Calibration choice, rate smoothing, and the pattern of tetrapod diversification according to the long nuclear gene RAG-1. Systematic Biology 56(4):543-563.

ICZN. 1999. International Code of Zoological Nomenclature. Fourth edition. The International Trust for Zoological Nomenclature, London, UK. BHL. The Code Online (ICZN).

Ivanova NV, DeWaard J, Hebert PDN. 2006. An inexpensive, automation friendly protocol for recovering high quality DNA. Molecular Ecology Notes 6:998-1002. https://doi.org/10.1111/j.1471-8286.2006.01428.x

Jin Y-T, Brown RP, Liu N-F. 2008. Cladogenesis and phylogeography of the lizard Phrynocephalus vlangalii (Agamidae) on the Tibetan Plateau. Molecular Ecology 17:1971-1982. https://doi.org/10.1111/j.1365-294X.2008.03721.x

Jin Y-T, Brown RP. 2013. Species history and divergence times of viviparous and oviparous Chinese toad-headed sand lizards (Phrynocephalus) on the Qinghai-Tibetan Plateau. Molecular Phylogenetics and 68:259-268. https://doi.org/10.1016/j.ympev.2013.03.022 
1142 Jin Y-T, Liu N-F. 2010. Phylogeography of Phrynocephalus erythrurus from the Qiangtang

1143

1144

1145

1146

1147

1148

1149

1150

1151

1152

1153

1154

1155

1156

1157

1158

1159

1160

1161

1162

1163

1164

1165

1166

1167

1168

1169

1170
Plateau of the Tibetan Plateau. Molecular Phylogenetics and Evolution 54:933-940. https://doi.org/10.1016/j.ympev.2009.11.003

Jin Y, Liu N, Brown RP. 2017. The geography and timing of genetic divergence in the lizard Phrynocephalus theobaldi on the Qinghai-Tibetan Plateau. Scientific Reports 7(2281): https://doi.org/10.1038/s41598-017-02674-4.

Jobb G. 2011. TREEFINDER version of March 2011. Munich, Germany. Distributed by the author at www.treefinder.de.

Kamali K, Anderson SC. 2015. A new Iranian Phrynocephalus (Reptilia: Squamata: Agamidae) from the hottest place on earth and a key to the genus Phrynocephalus in southwestern Asia and Arabia. Zootaxa 3904 (2):249-260. https://doi.org/10.11646/zootaxa.3904.2.4.

Kotlov AA. 2008. Species composition and distribution of amphibians and reptiles of southwestern Kulunda. Altaiskiy Zoologicheskiy Zhurnal 2:131-133. [in Russian]

Kuhle M. 1998. Reconstruction of the 2.4 million km2 late Pleistocene ice sheet on the Tibetan Plateau and its impact on the global climate. Quaternary International 45:71-108.

Lanfear R, Calcott B, Ho SYW, Guindon S. 2012. PartitionFinder: combined selection of partitioning schemes and substitution models for phylogenetic analyses. Molecular Biology and Evolution 29(6):1695-1701. https://doi.org/10.1093/molbev/mss020

Leache AD, Cole CJ. 2007. Hybridization between multiple fence lizard lineages in an ecotone: locally discordant variation in mitochondrial DNA, chromosomes, and morphology. Molecular Ecology 16:1035-1054. https://doi.org/10.1111/j.1365-294X.2006.03194.x

Li XZ, Dong GR, Chen HZ, Zheng HB, Jin HL, Jin J. 2001. Uplift processes of the QinghaiTibetan Plateau interpreted from the comparison of Yecheng section and Siwalik group. Journal of Desert Research 21:354-360. [in Chinese with English abstract]

Likhnova O. 1992. Biochemical systematics of toad agamas Phrynocephalus (Agamidae, Reptilia). Asian Herpetological Meeting, Huangshan: 46-47.

Lomolino MV, Sax DF, Riddle BR, Brown JH. 2006. The island rule and a research agenda for studying ecogeographical patterns. Journal of Biogeography 33(9):1503-1510. https://doi.org/10.1111/j.1365-2699.2006.01593.x 
1171 Ma C, Arias EF, Eubanks TM, Fey AL, Gontier A-M, Jacobs CS, Sovers OJ, Archinal BA,

1172

1173

1174

1175

1176

1177

1178

1179

1180

1181

1182

1183

1184

1185

1186

1187

1188

1189

1190

1191

1192

1193

1194

1195

1196

1197

1198

1199 Charlo P. 1998. The international celestial reference frame as realized by very long baseline interferometry. The Astronomical Journal 116: 5-6. https://doi.org/10.1086/300408

Macey JR, Ananjeva NB, Zhao EM, Wang YZ, Papenfuss TJ. 1993. An allozyme-based phylogenetic hypothesis for Phrynocephalus (Agamidae) and its implications for the historical biogeography of arid Asia. Proceedings of the First Asian Herpetological Meeting, China Forestry Press, Beijing: 349.

Macey JR, Schulte II JA, Fong JJ, Das I, Papenfuss TJ. 2006. The complete mitochondrial genome of an agamid lizard from the Afro-Asian subfamily Agaminae and the phylogenetic position of Bufoniceps and Xenagama. Molecular Phylogenetics and Evolution 39:291-297. https://doi.org/10.1016/j.ympev.2005.08.020

Macey JR, Schulte JA II, Larson A, Ananjeva NB, Wang Y, Rastegar-Pouyani N, Pethiyagoda R, Papenfuss TJ. 2000. Evaluating Trans-Tethys migration: an example using acrodont lizard phylogenetics. Systematic Biology 49(2):233.

Maddison WP and Maddison DR. 2017. Mesquite: a modular system for evolutionary analysis. Version 3.31. Available at: http://mesquiteproject.org

Maddison WP. 1991. Squared-change parsimony reconstructions of ancestral states for continuous-valued characters on a phylogenetic tree. Systematic Zoology 40(3):304-314. https://doi.org/10.2307/2992324

Manafzadeh S, Salvo G and Conti E. 2014. A tale of migrations from east to west: the IranoTuranian floristic region as a source of Mediterranean xerophytes. Journal of Biogeography 41:366-379. https://doi.org/10.1111/jbi.12185

Manilo V.V. 2000. Description of karyotypes of some species and subspecies of the genus Phrynocephalus (Sauria, Agamidae) from Central Asia. Vestnik zoologii 34(6):113-118. [in Russian]

Manilo VV. 2001. Cytogenetic review and evolution of karyotypes in the species of the genus Phrynocephalus Kaup, 1825 (Sauria, Agamidae) from the Eastern Palaearctic. Hamadryad 26(2):227-234. 
1200 Manilo VV, Golubev ML. 1993. Karyotype information on some toad agamas of the

1201

1202

1203

1204

1205

1206

1207

1208

1209

1210

1211

1212

1213

1214

1215

1216

1217

1218

1219

1220

1221

1222

1223

1224

1225

1226

1227

1228

1229

1230 Phrynocephalus species group (Sauria, Agamidae) of the former USSR. Asiatic Herpetological Research 5:105-108.

Martins EP. 1999. Estimating of ancestral states of continuous characters: a computer simulation study. Systematic Biology 48:642-650.

McGuire JA, Linkem CW, Koo MS, Hutchison DW, Lappin AK, Orange DI, Lemos-Espinal J, Riddle BR, Jaeger JR. 2007. Mitochondrial introgression and incomplete lineage sorting through space and time: phylogenetics of crotaphytid lizards. Evolution 61: 2879-2897. https://doi.org/10.1111/j.1558-5646.2007.00239.x

Melnikov DA, Melnikova E, Nazarov R, Rajabizadeh M, Al-Johany A, Amr ZS, Ananjeva NB. 2014. Taxonomic revision of Phrynocephalus arabicus Anderson, 1984 [sic] complex with description of a new species from Ahvaz, southwestern Iran. Russian Journal of Herpetology 21(2):149-159.

Melville J, Hale J, Mantziou G, Ananjeva NB, Milto K, Clemann N. 2009. Historical biogeography, phylogenetic relationships and intraspecific diversity of agamid lizards in the Central Asian deserts of Kazakhstan and Uzbekistan. Molecular Phylogenetics and Evolution 53:99-112. https://doi.org/10.1016/j.ympev.2009.05.011

Metallinou M, Arnold NE, Crochet PA, Geniez P, Brito JC, Lymberakis P, El Din SB, Sindaco R, Robinson M, Carranza S. 2012. Conquering the Sahara and Arabian deserts: systematics and biogeography of Stenodactylus geckos (Reptilia: Gekkonidae). BMC Evolutionary Biology 12:258. https://doi.org/10.1186/1471-2148-12-258

Molnar P. 2005. Mio-Pliocene growth of the Tibetan Plateau and evolution of East Asian climate. Palaeontologia Electronica 8(1):1-23.

Moody SM, Hutterer HR. 1978. Karyotypes of the agamid lizard Lyriocephalus scutatus (L 1758), with a brief review of the chromosomes of the lizard family Agamidae. Bönn Zoological Bulletin 29:165-170.

Moody SM. 1980. Phylogenetic and historical biogeographical relationships of the genera in the family Agamidae (Reptilia: Lacertilia). PhD thesis, Univ. Michigan, Ann Arbor: 373.

Moutherau F, Lacombe O, Vergés J. 2012. Building the Zagros collisional orogen: timing, strain distribution and the dynamics of Arabia/Eurasia Plate convergence. Tectonophysics 532535:27-60. https://doi.org/10.1016/j.tecto.2012.01.022 
1231 Ng J, Glor RE. 2011. Genetic differentiation among populations of a Hispaniolan trunk anole

1232

1233

1234

1235

1236

1237

1238

1239

1240

1241

1242

1243

1244

1245

1246

1247

1248

1249

1250

1251

1252

1253

1254

1255

1256

1257

1258

1259

1260 that exhibit geographical variation in dewlap colour. Molecular Ecology 20:4302-4317. https://doi.org/10.1111/j.1365-294X.2011.05267.x

Nguyen SN, Zhou W-W, Le T-NT, Tran A-DT, Jin J-Q, Vo BD, Nguyen LT, Nguyen TT, Nguyen TQ, Hoang DD, Orlov NL, Che J, Murphy RW, Zhang Y-P. 2017. Cytonuclear discordance, cryptic diversity, complex histories, and conservation needs in Vietnamese bent-toed geckos of the Cyrtodactylus irregularis species complex. Russian Journal of Herpetology 24 (2):133-154.

Nikolsky AM. 1916. Reptilia. Vol. II. Ophidia. The fauna of Russia and adjacent countries. Imperial Academy of Science Press, Petrograd: 349. [in Russian]

Noble DWA, Qi Y, Fu J. 2010. Species delineation using Bayesian model-based assignment tests: a case study using Chinese toad-headed agamas (genus Phrynocephalus). BMC Evolutionary Biology 10:197. https://doi.org/10.1186/1471-2148-10-197

Orlova VF, Poyarkov NA, Chirikova MA, Nazarov RA, Munkhbayar M, Munkhbayar Kh, Terbish Kh. 2017. MtDNA differentiation and taxonomy of Central Asian racerunners of Eremias multiocellata-E. przewalskii species complex (Squamata, Lacertidae). Zootaxa 4282(1):001-042. https://doi.org/10.11646/zootaxa.4282.1.1.

Orlova VF, Dunayev EA, Nazarov RA, Terbish Kh, Erdentushig P. 2014. Materials on the southwestern Mongolia herpetofauna. Sovremennaya Herpetologiya 14(1/2):32-43. [in Russian]

Pan Y. 1999. Formation and uplifting of the Qinghai-Tibetan Plateau. Frontiers of Earth Science 6:153-163. [in Chinese with English abstract]

Pang J, Wang Y, Zhong Y, Hoelzele AR, Papenfuss TJ, Zeng X, Ananjeva NB, Zhang YP. 2003. A phylogeny of Chinese species in the genus Phrynocephalus (Agamidae) inferred from mitochondrial DNA sequences. Molecular Phylogenetics and Evolution 27:398-409.

Pedall I, Fritz U, Stuckas H, Valdeon A, Wink M. 2010. Gene flow across secondary contact zones of the Emys orbicularis complex in the western Mediterranean and evidence for extinction and re-introduction of pond turtles on Corsica and Sardinia (Testudines: Emydidae). Journal of Zoological Systematics and Evolutionary Research 49:44-57. https://doi.org/10.1111/j.1439-0469.2010.00572.x 
1261 Peng Z, Ho SYW, Zhang Y, He S. 2006. Uplift of the Tibetan plateau: evidence from divergence

1262

1263

1264

1265

1266

1267

1268

1269

1270

1271

1272

1273

1274

1275

1276

1277

1278

1279

1280

1281

1282

1283

1284

1285

1286

1287

1288

1289

1290

1291 times of glyptosternoid catfishes. Molecular Phylogenetics and Evolution 39:568-572. https://doi.org/10.1016/j.ympev.2005.10.016

Pisano J, Condamine FL, Lebedev V, Bannikova A, Quéré JP, Shenbrot GI, Pages M, Michaux JR. 2015. Out of Himalaya: the impact of past Asian environmental changes on the evolutionary and biogeographical history of Dipodoidea (Rodentia). Journal of Biogeography 42(5):856-870. https://doi.org/10.1111/jbi.12476

Pook CE, Joger U, Stümpel N, Wüster W. 2009. When continents collide: Phylogeny, historical biogeography and systematics of the medically important viper genus Echis (Squamata: Serpentes: Viperidae). Molecular Phylogenetics and Evolution 53:792-807. https://doi.org/10.1016/j.ympev.2009.08.002

Popov SV, Akhmeteyev MA, Lopatin AV, Bugrova AM, Sychevskaya EK, Kopp ML, Szherba IG, Zaporozhets NI, A.S., Andreeva-Grigorovich, Nikolaeva IA. 2009. Paleogeography and biogeography of Paratethys basin. Vol. I. Late Eocene-Early Miocene. Nauchny Mir 200. [in Russian]

Popov SV., Rögl F, Rozanov AY, Steininger FF, Shcherba IG, Kovac K. 2004. Lithologicalpaleographic maps of Paratethis. 10 maps Late Eocene to Pliocene. Courier Forschungsinstitut Senckenberg, Frankfurt 46.

Prasad GVR, Bajpai G. 2008. Agamid lizards from the early Eocene of western India: oldest Cenozoic lizards from South Asia. Palaeontology Electronica 11:1-19.

Qi Y, Yang W, Lu B, Fu J. 2013. Genetic evidence for male-biased dispersal in the Qinghai toad-headed agamid Phrynocephalus vlangalii and its potential link to individual social interactions. Ecology and Evolution 3(5):1219-30. https://doi.org/10.1002/ece3.532

Rahiamian H, Shafiei S, Rastegar Pouyani N, Rastegar Pouyani E. 2015. Phylogenetic relationships of the gray-toad agama, Phrynocephalus scutellatus (Olivier, 1807), species $\begin{array}{lllll}\text { complex from } & \text { Iran. } & \text { Zootaxa } & 3990 & \text { (3):369-380. }\end{array}$ https://doi.org/10.11646/zootaxa.3990.3.3

Rambaut A, Drummond AJ. 2007. Tracer v1. 5. Available at http:// beast.bio.ed.ac.uk/Tracer.

Ramstein G, Fluteau F, Besse F, Joussaume S. 1997. Effect of orogeny, plate motion and landsea distribution on Eurasian climate change over the past 30 million years. Nature 386:788-795. 
1292 Ree RH, Moore BR, Webb CO, Donoghue MJ. 2005. A likelihood framework for inferring the

1293

1294

1295

1296

1297

1298

1299

1300

1301

1302

1303

1304

1305

1306

1307

1308

1309

1310

1311

1312

1313

1314

1315

1316

1317 evolution of geographic range on phylogenetic trees. Evolution 59:2299-2311. https://doi.org/10.1111/j.0014-3820.2005.tb00940.x

Ree RH, Smith SA. 2008. Maximum likelihood inference of geographic range evolution by dispersal, local extinction, and cladogenesis. Systematic Biology 57:4-14. https://doi.org/10.1080/10635150701883881

Renner S. 2016. Available data point to a 4-km-high Tibetan Plateau by $40 \mathrm{Ma}$, but 100 molecular-clock papers have linked supposed recent uplift to young node ages. Journal of Biogeography 43(8):1479-1487. https://doi.org/10.1111/jbi.12755

Renoult JP, Geniez P, Bacquet P, Benoit L, Crochet P-A. 2009. Morphology and nuclear markers reveal extensive mitochondrial introgressions in the Iberian Wall Lizard species complex. Molecular Ecology 18:4298-4315. https://doi.org/10.1111/j.1365-294X.2009.04351.x

Rieppel O, Walker A, Odhiambo I. 1992. A preliminary report on a fossil chamaeoleonine (Reptilia: Chamaeleoninae) skull from the Miocene of Kenya. Journal of Herpetology 26:77-80.

Rögl F. 1998. Paleogeographic considerations for Mediterranean and Paratethys seaways (Oligocene and Miocene). Annalen des Naturhistorischen Museums in Wien 99A: 279331.

Rögl F. 1999. Mediterranean and Paratethys. Facts and hypotheses of an Oligocene to Miocene paleogeography (short overview). Geologica Carpathica 50(4):339-349.

Ronquist F, Huelsenbeck JP. 2003. MrBayes 3: Bayesian phylogenetic inference under mixed models. Bioinformatics 19(12):1572-1574. https://doi.org/10.1093/bioinformatics/btg180

Scherler L, Mennecart B, Hiard F, Becker D. 2013. Evolutionary history of hoofed mammals during the Oligocene-Miocene transition in Western Europe. Swiss Journal of Geosciences 106:349-369. https://doi.org/10.1007/s00015-013-0140-x

Schulter D, Price T, Mooers AØ, Ludwig D. 1997. Likelihood of ancestor states in adaptive radiation. Evolution 51:1699-1711.

Shackleton RM, Chang C. 1988. Cenozoic uplift and deformation of the Tibetan Plateau: the geomorphological evidence. The Geological Evolution of Tibet. Philosophical Transactions of the Royal Society 327(1594):365-377. 
1322 Sharma RC. 1978. A new species of Phrynocephalus Kaup (Reptilia: Agamidae) from the

1323

1324

1325

1326

1327

1328

1329

1330

1331

1332

1333

1334

1335

1336

1337

1338

1339

1340

1341

1342

1343

1344

1345

1346

1347

1348

1349

Rajasthan Desert, India, with notes on ecology. Bulletin of the Zoological Survey of India 1(3):291-294.

Shenbrot G, Bannikova A, Giraudoux P, Quere JP, Raoul F, Lebedev V. 2017. A new recent genus and species of three-toed jerboas (Rodentia: Dipodinae) from China: a living fossil? Journal of Zoological Systematics and Evolutionary Research. 55:356-368. https://doi.org/10.1111/jzs.12182

Shi Y, Li J, Li B, Pan B, Fang X, Yao T, Wang S, Cui Z, Li S. 1998. Uplift and environmental evolution of Qinghai-Xizang (Tibetan) Plateau. Formation, Evolution and Development of Qinghai-Xizang (Tibetan) Plateau: 73-138. [in Chinese]

Shimodaira H. 2002. An approximately unbiased test of phylogenetic tree selection. Systematic Biology 51(3):492-508.

Shoo L, Rose R, Doughty P, Austin JJ, Melville J. 2008. Diversification patterns of pebblemimic dragons are consistent with historical disruption of important habitat corridors in arid Australia. Molecular Phylogenetics and Evolution 48:528-542. https://doi.org/10.1016/j.ympev.2008.03.022

Šmíd J, Carranza S, Kratochvil L, Gvozdik V, Nasher AK, Moravec J. 2013. Out of Arabia: a complex biogeographic history of multiple vicariance and dispersal events in the gecko genus Hemidactylus (Reptilia: Gekkonidae). PLoS ONE 8(5):1-14. https://doi.org/10.1371/journal.pone.0064018

Smit JHW, Cloetingh SAPL, Burov E, Tesauro M., Sokoutis D, Kaban M. 2013. Interference of lithospheric folding in western Central Asia by simultaneous Indian and Arabian plate indentation. Tectonophysics 602:176-193. https://doi.org/10.1016/j.tecto.2012.10.032

Sokolovsky VV. 1975. Karyotypes and taxonomy of lizards of the family Agamidae. Biologicheskiye issledovaniya na Dalnem Vostoke, Vladivostok, 107-111. [in Russian]

Solovyeva EA. 2017. The position of Phrynocephalus rossikowi (Reptilia, Agamidae) according to mtDNA from old museum specimen. SEH 19th European Congress of Herpetology. Programme and Abstracts. University of Salzburg, 18-23 September 2017:256. 
1350 Solovyeva EN, Dunayev EA, Poyarkov NA. 2012. Interspecific taxonomy of sunwatcher

1351

1352

1353

1354

1355

1356

1357

1358

1359

1360

1361

1362

1363

1364

1365

1366

1367

1368

1369

1370

1371

1372

1373

1374

1375

1376

1377

1378

1379

1380

toadhead agama species complex (Phrynocephalus helioscopus, Squamata). Zoologicheskiy Zhurnal 91(11):1377-1396. [in Russian]

Solovyeva EN, Poyarkov NA, Dunayev EA, Duysebayeva TN, Bannikova AA. 2011. Molecular differentiation and taxonomy of the sunwatcher toad headed agama species complex Phrynocephalus superspecies helioscopus (Pallas 1771) (Reptilia: Agamidae). Russian Journal of Genetics 47(7):952-967.

Solovyeva EN, Poyarkov NA, Dunayev EA, Nazarov RA, Lebedev VS, Bannikova AA. 2014. Phylogenetic relationships and subgeneric taxonomy of toad-headed agamas Phrynocephalus (Reptilia, Squamata, Agamidae) based on mitochondrial DNA sequence data. Doklady Biological Sciences 455:119-124. https://doi.org/10.1134/S0012496614020148

Sun J, Liu T. 2006. The Age of the Taklimakan Desert. Science 312(5780):1621. https://doi.org/10.1126/science.1124616

Swofford DL. 2002. Phylogenetic analysis using parsimony (*and other methods). Version 4. Sunderland MA Sinauer Associates.

Szczerbak [Shcherbak] NN. 1994. Zoogeographic analysis of reptiles of Turkmenistan. Biogeography and Ecology of Turkmenistan 307-328.

Szczerbak NN. 2003. Guide to the Reptiles of the Eastern Palearctic. Golubev ML, Ed. Malabar (Florida): Krieger Publishing, $260 \mathrm{p}$.

Tamura K, Stecher G, Peterson D, Filipski A, Kumar S. 2013. MEGA6: Molecular Evolutionary Genetics Analysis version 6.0. Molecular Biology and Evolution 30: 2725-2729. https://doi.org/10.1093/molbev/mst197

Thompson JD, Higgins DG, Gibson TJ. 1994 CLUSTAL W: improving the sensitivity of progressive multiple sequence alignment through sequence weighting, position-specific gap penalties and weight matrix choice. Nucleic Acids Research 22(22):4673-80.

Toews DP, Brelsford A. 2012. The biogeography of mitochondrial and nuclear discordance in animals. Molecular Ecology 21:3907-3930. https://doi.org/10.1111/j.1365294X.2012.05664.X

Townsend TM, Alegre RE, Kelley ST, Wiens JJ, Reeder TW. 2008. Rapid development of multiple nuclear loci for phylogenetic analysis using genomic resources: an example 
1381

1382

1383

1384

1385

1386

1387

1388

1389

1390

1391

1392

1393

1394

1395

1396

1397

1398

1399

1400

1401

1402

1403

1404

1405

1406

1407

1408

1409

1410

1411

from squamate reptiles. Molecular Phylogenetics and Evolution 47(1):129-142. https://doi.org/10.1016/j.ympev.2008.01.008

Townsend TM, Mulcahy DG, Noonan BP, Sites JW, Kuczynski CA, Wiens JJ, Reeder TW. 2011. Phylogeny of iguanian lizards inferred from 29 nuclear loci, and a comparison of concatenated and species-tree approaches for an ancient, rapid radiation. Molecular Phylogenetics and

Evolution

61(2011):363-380. https://doi.org/10.1016/j.ympev.2011.07.008

Uetz P, Hošek J. 2016. The Reptile Database. Available at http://www.reptile-database.org, accessed March 232016.

Urquhart J, Wang Y, Fu J. 2009. Historical vicariance and male-mediated gene flow in the toadheaded lizards Phrynocephalus przewalskii. Molecular Ecology 18:3714-3729. https://doi.org/10.1111/j.1365-294X.2009.04310.x

Wang Y, Fu J. 2004. Cladogenesis and vicariance patterns in the toad-headed lizard Phrynocephalus versicolor species complex. Copeia 2:199-206. https://doi.org/10.1643/CG-03-082R1

Wang YZ, Macey JR. 1993. On the ecologico-geographic differentiation of Chinese species of the genus Phrynocephalus. Proceedings of the First Asian Herpetological Meeting 147.

Weise V. 1974. The slope development and plain formation in the deserts of the Iranian highlands. Wurzburger Geographische Arbeiten 24:21-26.

Wermuth H. 1967. Liste der rezenten Amphibien und Reptilien. Agamidae. Das Tierreich $86: 127$.

Whiteman RS. 1978. Evolutionary history of the lizard genus Phrynocephalus (Lacertilia, Agamidae). M.A. Thesis, Fullerton, California State University 113.

Xia X, Hu W. 1993. The resources and environment in the Taklimakan Desert. Science in China (Series B) 23(8):889-896. [in Chinese]

Yang Z. 2007. PAML 4: phylogenetic analysis by maximum likelihood. Molecular Biology and Evolution 24(8):1586-1591. https://doi.org/10.1093/molbev/msm088

Yang SJ, Yin ZH, Ma XM, Lei FM. 2006. Phylogeography of ground tit (Pseudopodoces humilis) based on mtDNA: evidence of past fragmentation on the Tibetan plateau. Molecular Phylogenetics and Evolution 41:257-265. https://doi.org/10.1016/j.ympev.2006.06.003 
1412 Yuan W, Carter A, Dong J, Bao Z, An Y, Guo Z. 2006. Mesozoic-Tertiary exhumation history

1413

1414

1415

1416

1417

1418

1419

1420

1421

1422

1423

1424

1425

1426

1427

1428

1429

1430

1431 of the Altai Mountains, northern Xinjiang, China: new constraints from apatite fission track data. Tectonophysics 412:183-193. https://doi.org/10.1016/j.tecto.2005.09.007

Zachos J, Pagani M, Sloan L, Thomas E, Billups K. 2001. Trends, rhythms, and aberrations in global climate $65 \mathrm{Ma}$ to present. Science 292:686-693. https://doi.org/10.1126/science.1059412

Zarza E, Reynoso VH, Brent C. 2011. Discordant patterns of geographic variation between mitochondrial and microsatellite markers in the Mexican black iguana (Ctenosaura pectinata) in a contact zone. Journal of Biogeography 38:1394-1405. https://doi.org/10.1111/j.1365-2699.2011.02485.x

Zeng XM, Wang YZ, Liu ZJ, Fang ZL, Wu GF, Papenfuss TJ, Macey JR. 1997. Karyotypes of nine species in the genus Phrynocephalus, with discussion of karyotypic evolution of Chinese Phrynocephalus. Acta Zoologica Sinica 43:399-410.

Zerova GA, Chkhikvadze VM. 1984. The review of Cenozoic lizards and snakes in USSR. News. Georgian SSR Academy of Sciences. Series: Biology 10:319-325. [in Russian]

Zhang Q, Xia L, He J, Wu Y, Fu J, Yang Q. 2010. Comparison of phylogeographic structure and population history of two Phrynocephalus species in the Tarim Basin and adjacent areas. Molecular Phylogenetics and Evolution 57(3):1091-104. https://doi.org/10.1016/j.ympev.2010.10.003

Zhao EM, Adler K. 1993. Herpetology of China. Published by Society for the Study of Amphibians and Reptiles.

Zhao EM, Zhao KT, Zhou KY. 1999. Fauna Sinica. Reptilia. Vol. 2. Squamata. Lacertilia. Beijing: Science Press 394.

Zheng H, Wei X, Tada R, Clift PD, Wang B, Jourdan F, Wang P, He M. 2015. Late Oligoceneearly Miocene birth of the Taklimakan Desert. Proceedings of National Academy of Sciences USA 112(25):7662-7667. https://doi.org/10.1073/pnas.1424487112 


\section{Table $\mathbf{1}$ (on next page)}

Uncorrected $p$-distances for concatenated sequences of nuDNA (above diagonal) and mtDNA genes (below diagonal) (\%) for species groups of Phrynocepahlus (1-11).

Values on the diagonal correspond to average uncorrected ingroup $p$-distances for mtDNAInuDNA genes (\%), respectively. 
1

\begin{tabular}{|c|l|c|c|c|c|c|c|c|c|c|c|c|}
\hline$\#$ & \multicolumn{1}{|c|}{ Group } & $\mathbf{1}$ & $\mathbf{2}$ & $\mathbf{3}$ & $\mathbf{4}$ & $\mathbf{5}$ & $\mathbf{6}$ & $\mathbf{7}$ & $\mathbf{8}$ & $\mathbf{9}$ & $\mathbf{1 0}$ & $\mathbf{1 1}$ \\
\hline $\mathbf{1}$ & arabicus-maculatus & $\mathbf{1 1 . 3 3 / 0 . 7 0}$ & 2.70 & 3.00 & 3.00 & 3.00 & 2.10 & 3.50 & 2.80 & 3.14 & 2.99 & 3.70 \\
\hline $\mathbf{2}$ & interscapularis & 17.71 & $\mathbf{1 1 . 4 5 / 1 . 5 7}$ & 3.40 & 3.60 & 3.60 & 2.50 & 3.60 & 3.40 & 3.40 & 3.39 & 3.81 \\
\hline $\mathbf{3}$ & scutellatus & 17.96 & 18.79 & - & 3.77 & 3.67 & 2.80 & 3.94 & 3.87 & 3.63 & 3.56 & 3.99 \\
\hline $\mathbf{4}$ & ocellatus & 17.08 & 17.24 & 18.54 & $\mathbf{7 . 0 9 / 1 . 0 0}$ & 1.52 & 2.50 & 1.57 & 2.90 & 1.73 & 1.56 & 2.00 \\
\hline $\mathbf{5}$ & strauchi & 16.45 & 16.28 & 18.40 & 11.92 & - & 2.40 & 1.60 & 2.82 & 1.57 & 1.53 & 2.00 \\
\hline $\mathbf{6}$ & mystaceus & 17.50 & 17.90 & 18.73 & 14.65 & 13.77 & $\mathbf{7 . 3 6 / 0 . 4}$ & 2.40 & 2.46 & 2.37 & 2.05 & 2.60 \\
\hline $\mathbf{7}$ & helioscopus & 18.08 & 17.68 & 18.99 & 14.81 & 14.14 & 15.64 & $\mathbf{1 1 . 0 9 / 1 . 1 4}$ & 2.92 & 1.77 & 1.67 & 2.07 \\
\hline $\mathbf{8}$ & Oreosaura & 16.47 & 16.08 & 18.09 & 14.26 & 13.59 & 15.04 & 14.80 & $\mathbf{7 . 9 3 / 0 . 7 5}$ & 2.85 & 2.50 & 3.16 \\
\hline $\mathbf{9}$ & axillaris & 16.91 & 16.79 & 18.24 & 14.53 & 12.72 & 13.98 & 13.47 & 13.52 & $\mathbf{2 . 1 8} /-$ & 1.08 & 1.75 \\
\hline $\mathbf{1 0}$ & versicolor & 16.89 & 16.89 & 18.12 & 14.65 & 13.21 & 15.78 & 15.03 & 13.65 & 13.64 & $\mathbf{6 . 9 5 / 0 . 3 1}$ & 0.60 \\
\hline $\mathbf{1 1}$ & guttatus & 16.92 & 17.01 & 18.27 & 14.40 & 13.10 & 15.16 & 14.91 & 13.69 & 13.48 & 9.28 & $\mathbf{5 . 8 4 / 0 . 5 8}$ \\
\hline
\end{tabular}

2 
Figure 1

Current distribution and species richness of the genus Phrynocephalus.

Color indicates the number of sympatric species of Phrynocephalus (from one to over four).

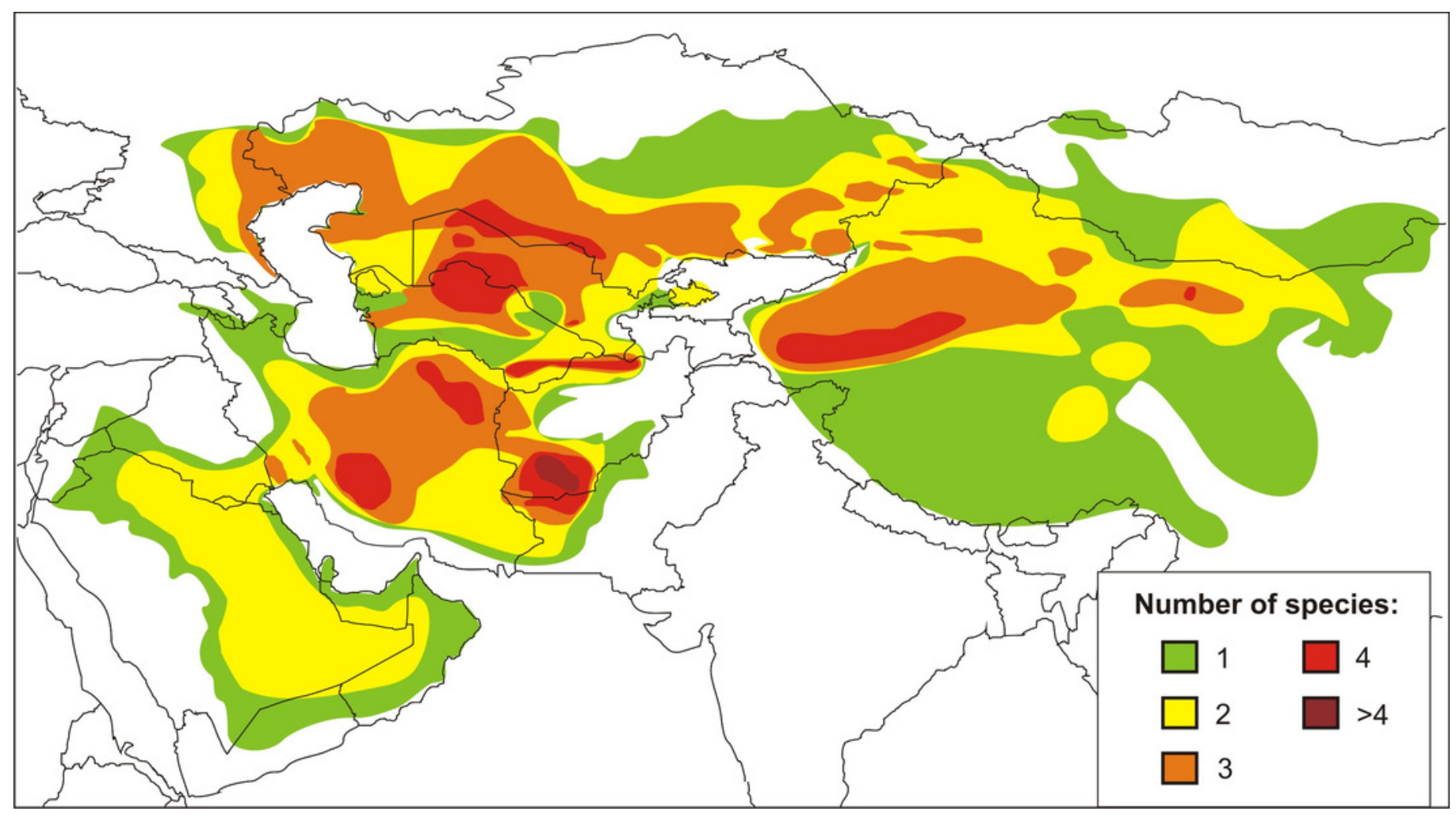


Figure 2

Mitochondrial genealogy of the genus Phrynocephalus on the base of $2703 \mathrm{bp}$ (partial COI, Cytb, ND2, ND4 sequences).

Node support values are given for ML BSP/MP BSP/BI BPP, respectively. Color marking of species groups corresponds to Fig. 3 and Supplementary Fig. S4.

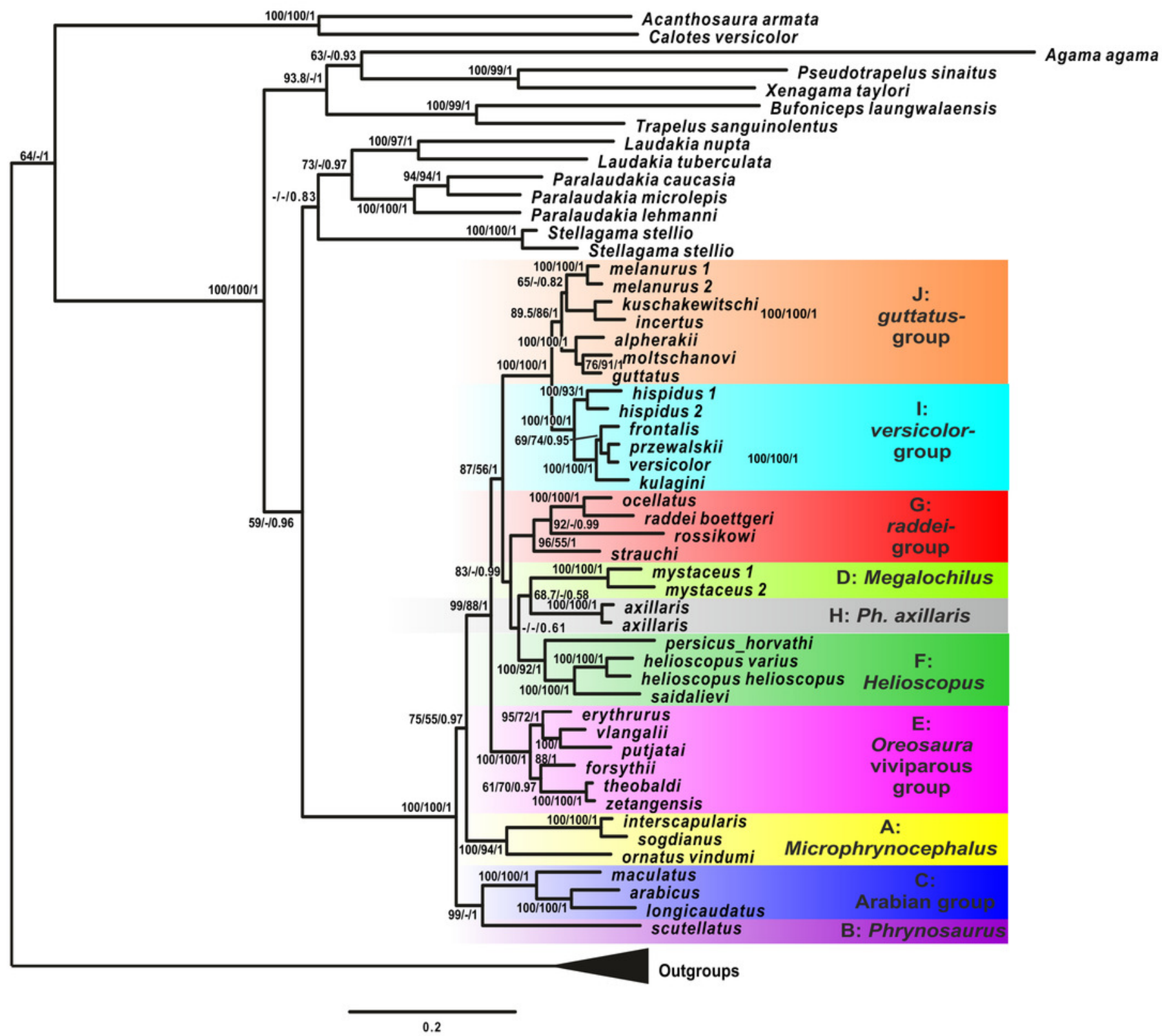


Figure 3

Phylogenetic ML tree reconstructed from concatenated alignment of the nuclear genes RAG-1, BDNF, AKAP9 and NKTR.

Numbers on tree nodes indicate bootstrap values (BS) and posterior probabilities for ML BSP/MP BSP/BI BPP, respectively. Color marking of species groups corresponds to mitochondrial lineages; see Fig. 2 and Supplementary Fig. S4. Thumbnails show representative species of each Phrynocephalus species group (to scale; note large size of $P$. mystaceus). Photographs by E.A. Dunayev and R.A. Nazarov.

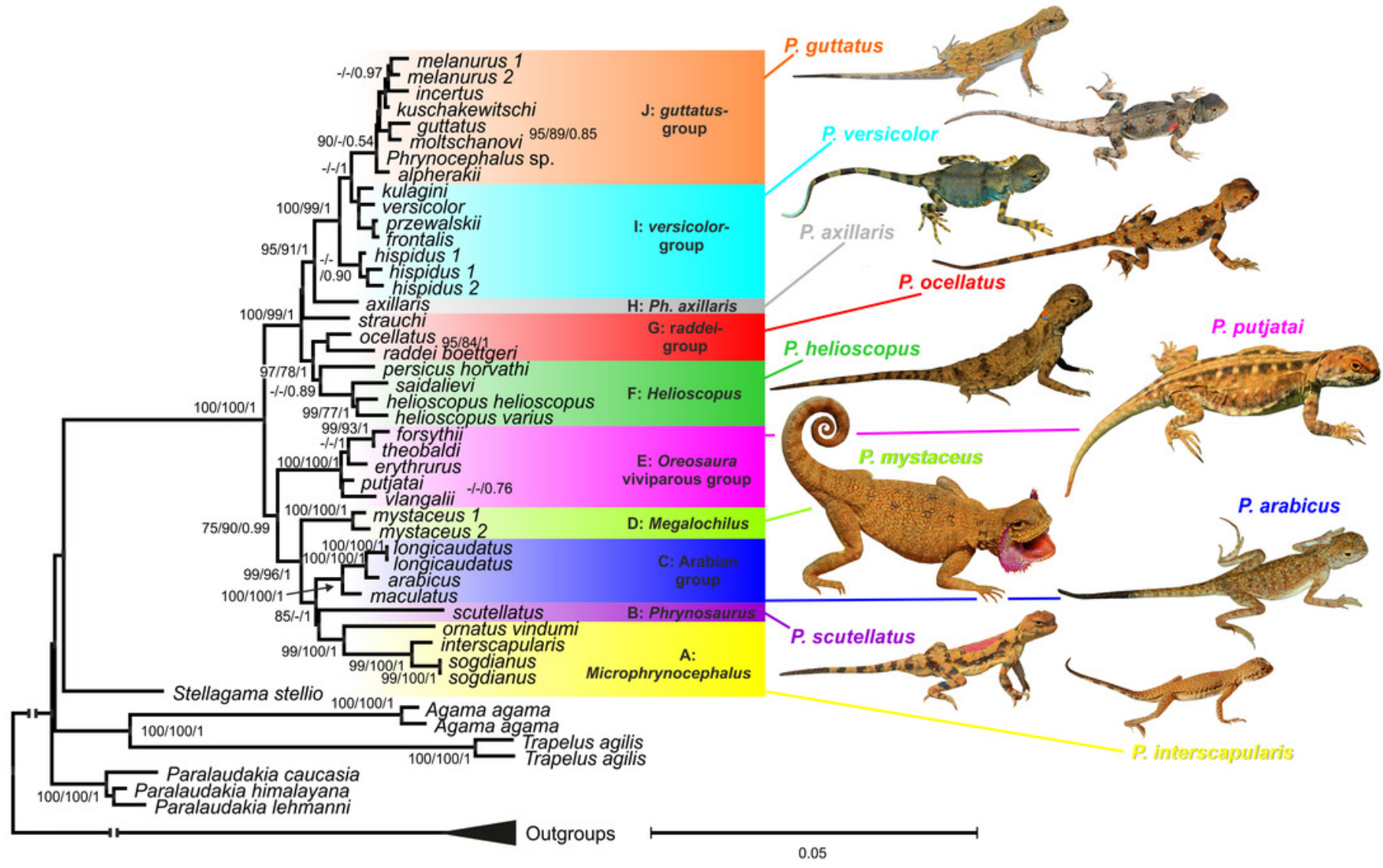


Figure 4

Species tree reconstructed by *BEAST analysis with the nuclear genes RAG-1, BDNF, AKAP9 and NKTR.

Bayesian posterior probabilities (BI BPP) values are given only for strongly supported nodes.

For Clades I-III definitions see Discussion.

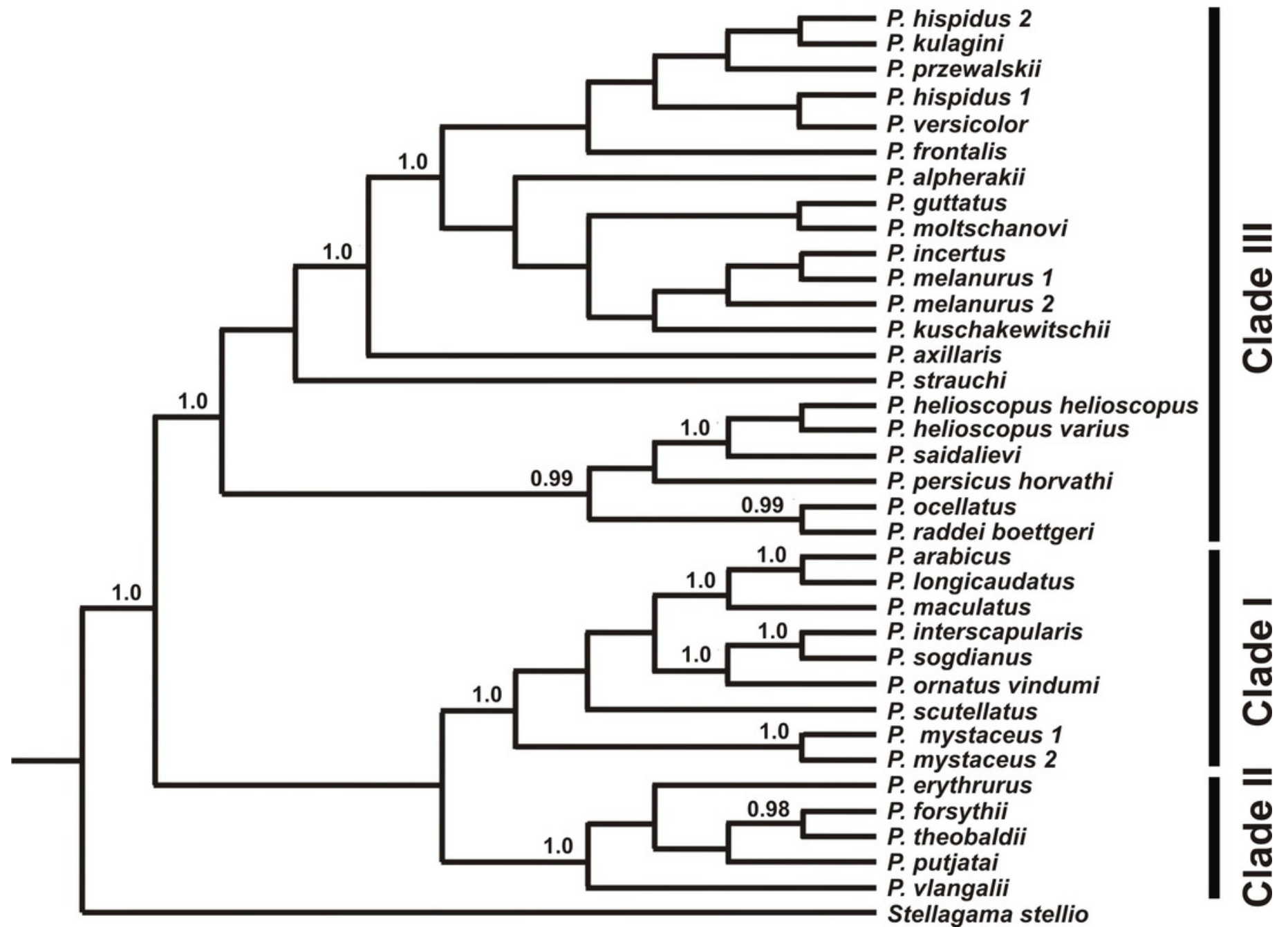




\section{Figure 5}

Differentiation of Phrynocephalus: BEAST chronogram on the base of nuDNA dataset with results of ancestral area modeling in Lagrange.

Abbreviations: GLB - "Gomphotherium-landbridge"; MMTO - Middle Miocene thermal optimum; MMCT - Middle Miocene climatic transition; PPCO - Pliocene-Pleistocene climate oscillations; AR - Near East and Arabia, MI -Asia Minor and Transcaucasia; KZ - Kazakhstan, North Caspian and Ciscaucasian deserts; CA - Central Asia; TU - Turan; TI - Tibet; ME Middle East. For biogeographic areas definitions see Supplementary File 2 and Supplementary Table S10. For paleogeographic reconstruction see Fig. 6. Node values correspond to estimated divergence times (in $\mathrm{Ma}$ ). Icons illustrate vicariant events, area expansion and local extinctions, respectively. Black line on the inset shows modern range of Phrynocephalus. Red line corresponds to temperature change during the Cenozoic; climatogram from Zachos et al. 2001. 


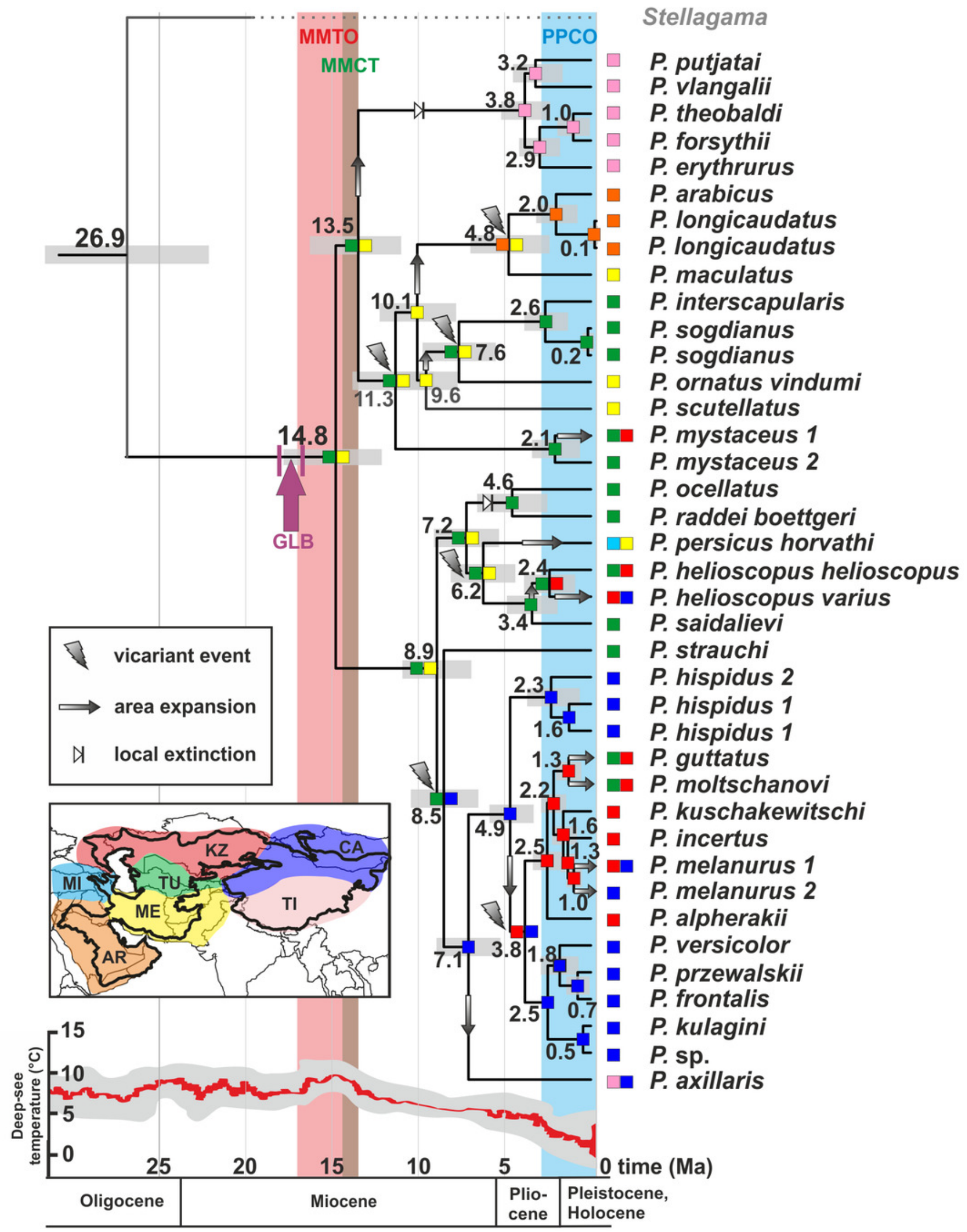




\section{Figure 6}

Paleogeography of Paratethys basin in late Cenozoic and the hypothetical scenario for Phrynocephalus.

Paleogeographic reconstructions are based on Rögl 1999; Popov et al. 2004; Popov et al. 2009 for early (A) and middle (B) Miocene and Pliocene (C). Question marks denote possible areas of distribution of the common ancestor of Phrynocephalus. GLB - "Gomphotheriumlandbridge" between Arabian plate and Asian mainland (18-17 Ma). Red dotted line possible range of Phrynocephalus; red arrows - possible dispersal routes; Latin numbers correspond to hypothetical distribution of main Phrynocephalus Clades I-III (see Discussion). 


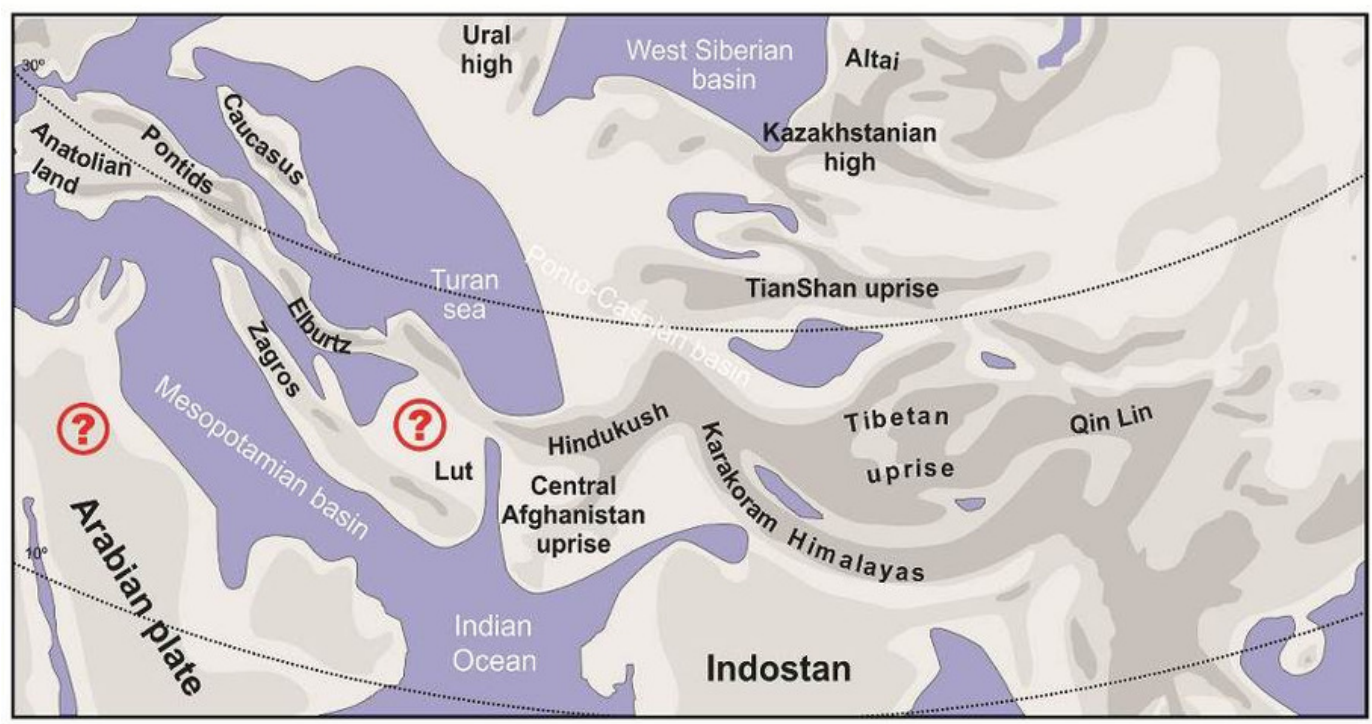

A. Miocene 20-19 Ma

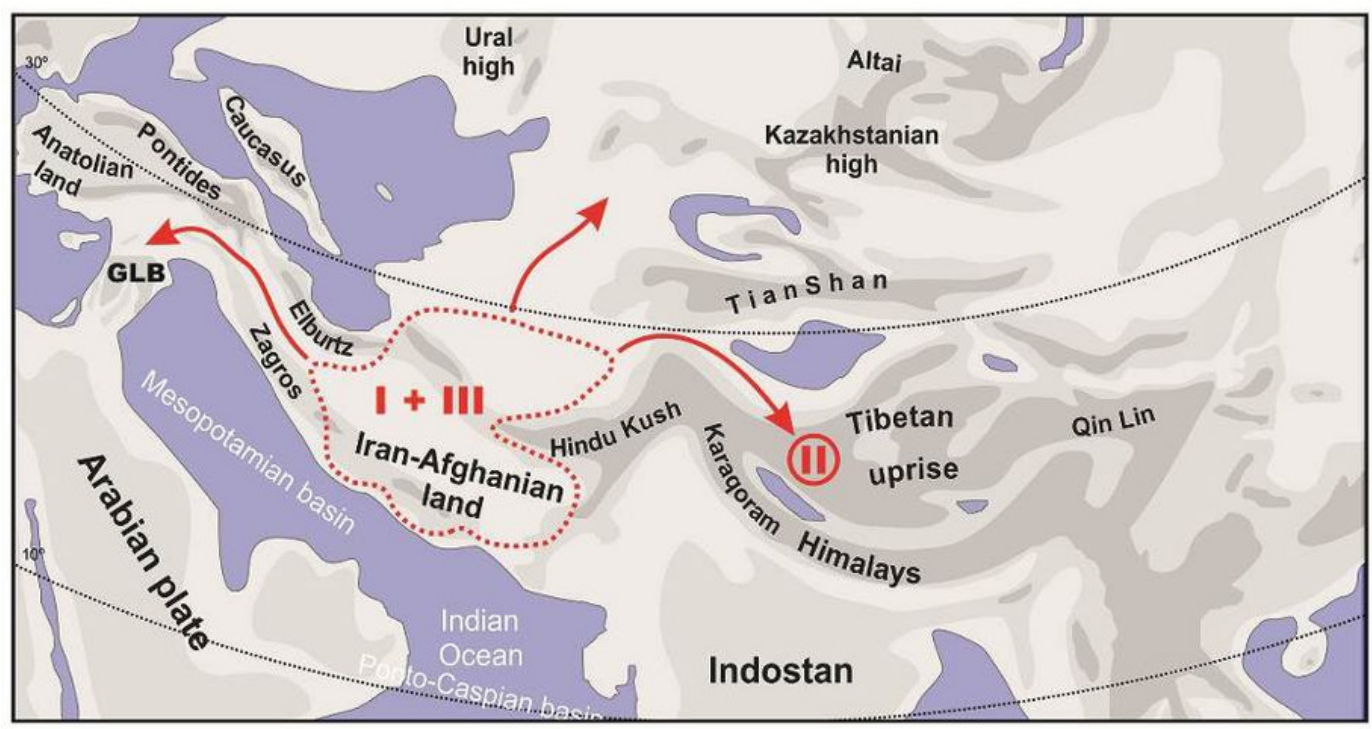

B. Miocene 15-13 Ma

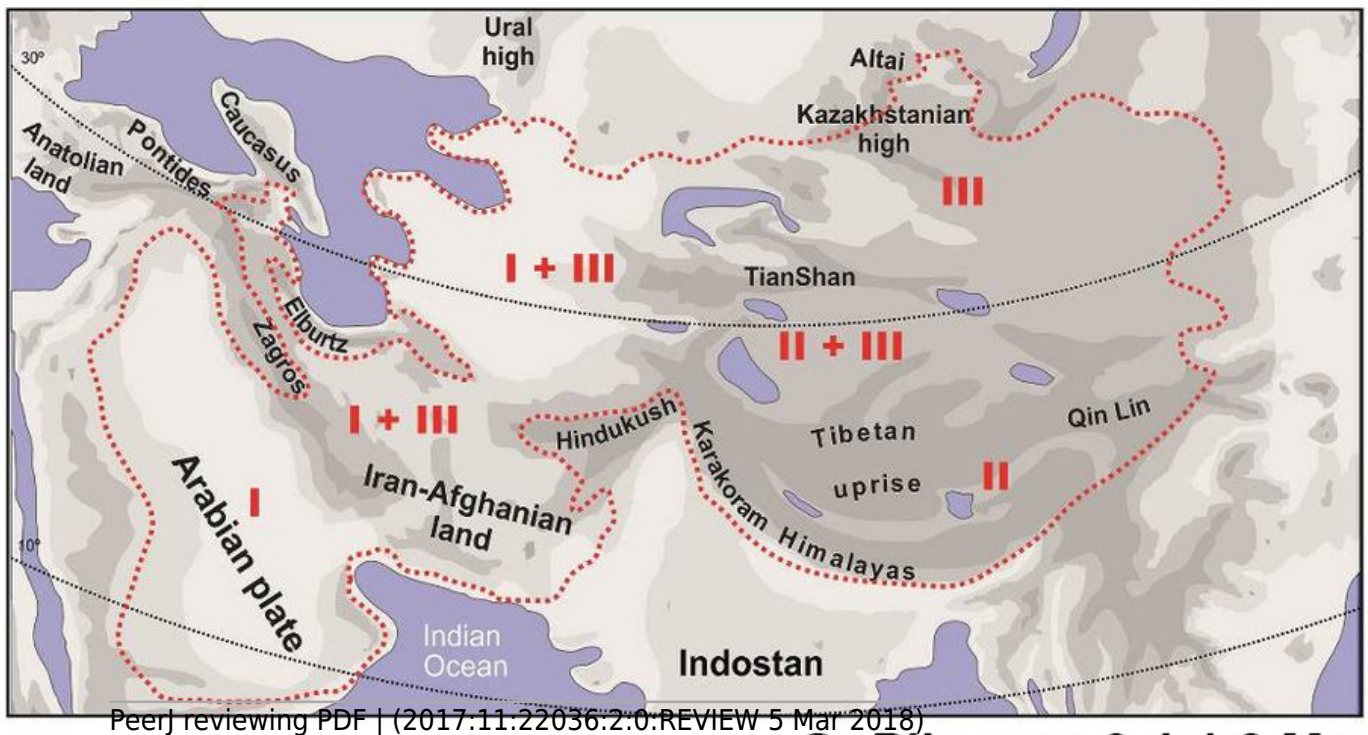

C. Pliocene 3.4-1.8 Ma 


\section{Figure 7}

Evolution of habitat preference in the Agaminae including the genus Phrynocephalus.

See Materials and Methods section and Supplementary Table S5 for habitat data and Supplementary Table $\mathbf{S 6}$ for step-matrix showing transition between substrate niche states.

Agaminae outgroups, except for Xenagama, Trapelus and Bufoniceps, inhabit large rocks and cliffs. Two lineages within the subfamily independently adapted to sandy habitats: the common ancestor of Bufoniceps and Trapelus and the ancestor of Phrynocephalus. Main groups within Phrynocephalus evolved adaptations to life on large loose sand dunes ( $P$. arabicus, P. mystaceus and Microphrynocephalus), stony and gravel highland deserts (subgenus Oreosaura) and on clay substrates with gravel ( $P$. helioscopus-P. raddei group). 


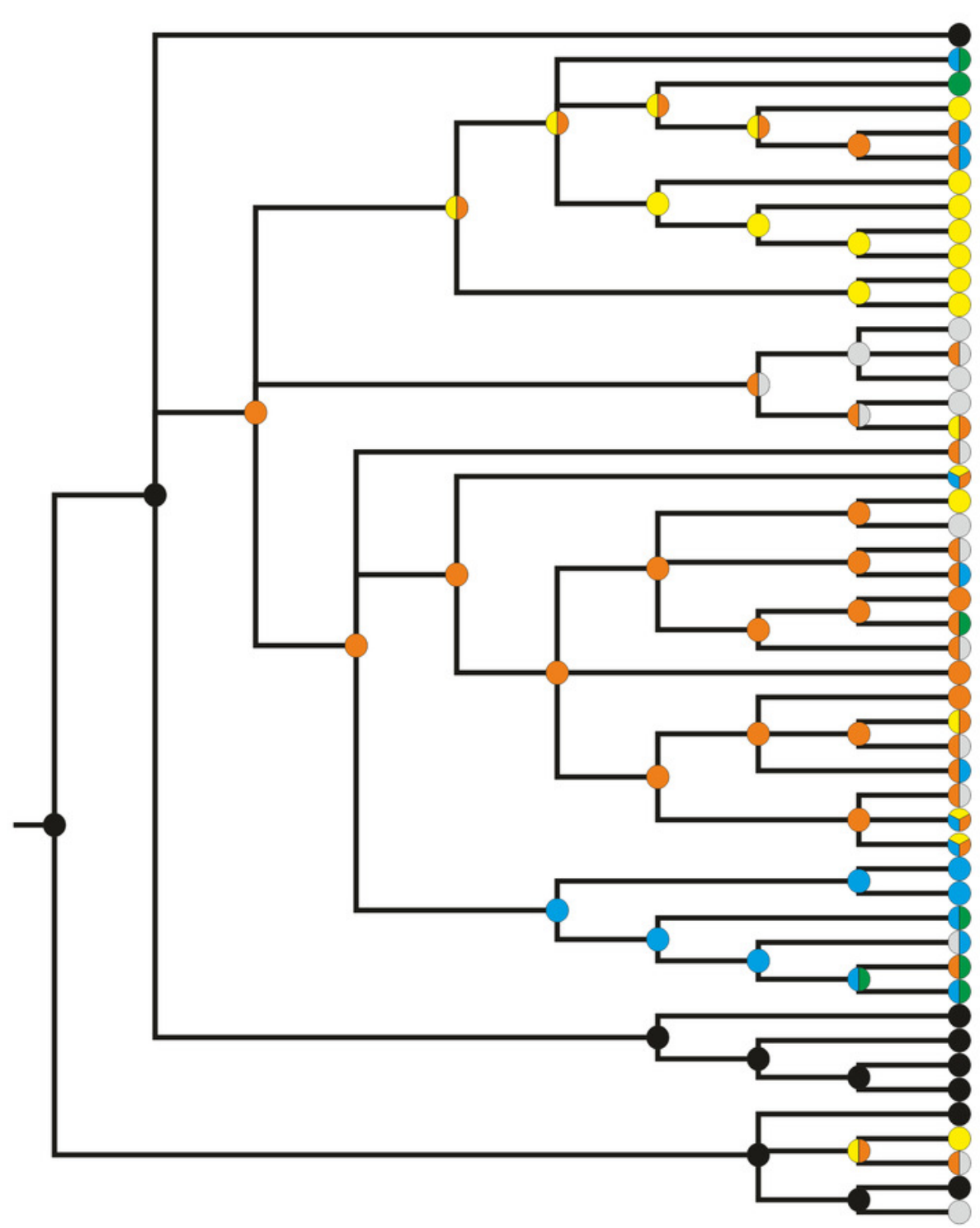

Stellagama stellio

$P$. scutellatus

P. maculatus

P. arabicus

$P$. longicaudatus

$P$. Iongicaudatus

$P$. ornatus vindumi

P. interscapularis

$P$. sogdianus

$P$. sogdianus

P. mystaceus 1

P. mystaceus 2

P. putjatai

$P$. vlangalii

P. erythrurus

$P$. theobaldi

P. forsythii

P. strauchi

$P$. axillaris

P. melanurus 1

P. melanurus 2

P. kuschakewitschii

$P$. incertus

P. moltschanovi

$P$ guttatus

$P$. alpherakii

$P$ sp.

$P$. frontalis

P. przewalskii

$P$. versicolor

$P$ kulagini

P. hispidus 2

P. hispidus 1

P. hispidus 1

$P$. ocellatus

$P$. raddei boettgeri

$P$. persicus horvathi

P. saidalievi

$P$. helioscopus varius

P. helioscopus helioscopus

Laudakia nupta

Paralaudakia caucasia

Paralaudakia himalayana

Paralaudakia lehmanni

Agama agama

Bufoniceps laungwalaensis Trapelus agilis

Pseudotrapelus sinaitus

Xenagama taylori
1.0
(1) loose sand dunes
(2) sands with clay or gravel
(3) gravel

(4) clay soils with gravel

(5) clay soils and salines

(6) large rocks and cliffs 


\section{Figure 8}

Body-size evolution among Agaminae including genus Phrynocephalus.

See Supplementary Table S5 for maximum SVL data. Color of branches corresponds to SVL $L_{\max }$ (see legend). Rock-dwelling Laudakia s.l. are characterized by larger body size, while the common ancestor of Phrynocephalus was likely smaller than other Agaminae; sand-dwelling Microphrynocephalus (P. ornatus-P. interscapularis group) and Megalochilus ( $P$. mystaceus group) represent the most miniaturized and the largest lineages within the genus, respectively. 


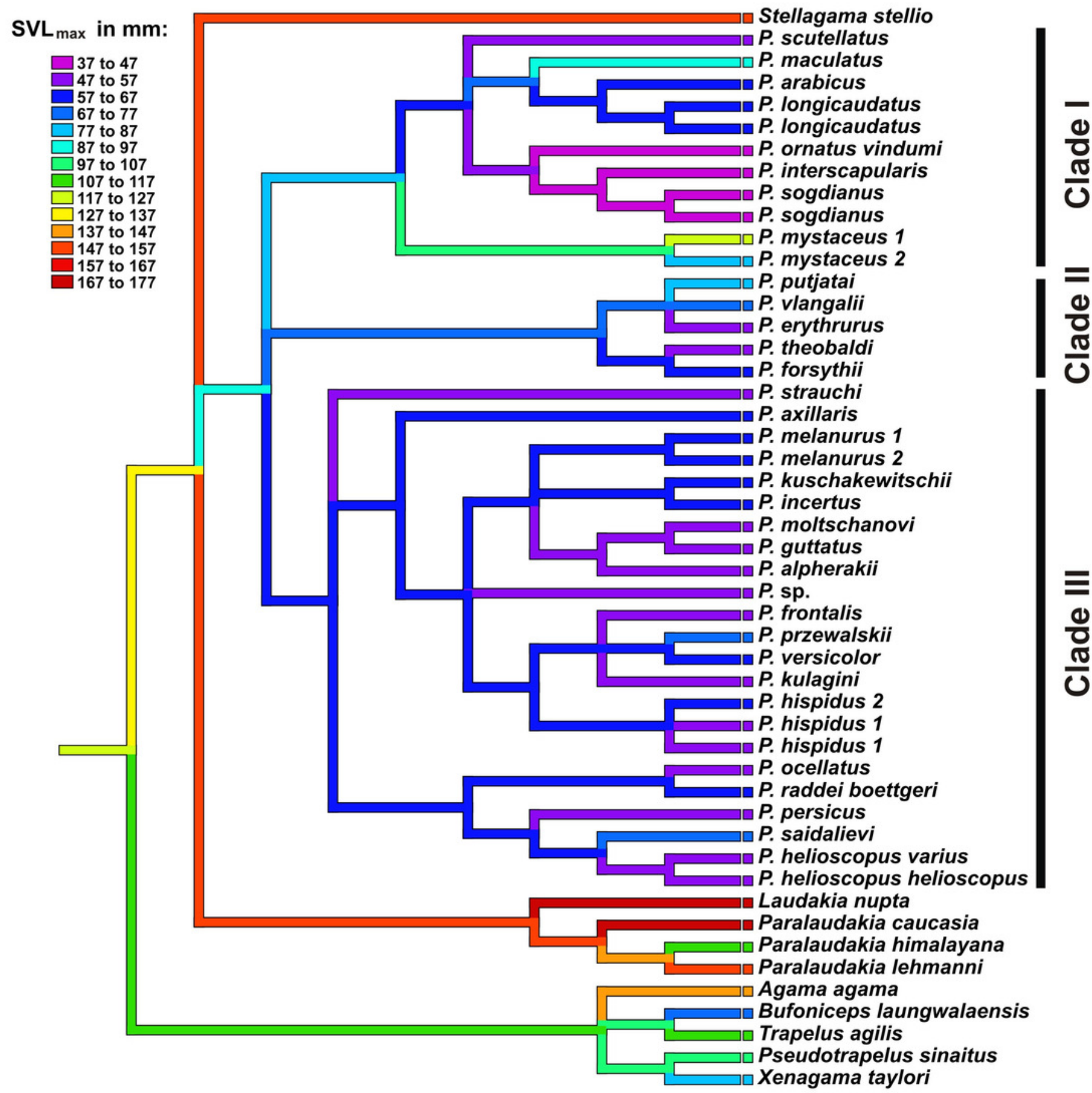

